\title{
Investigation of Dipole Antenna Loaded with DPS and DNG Materials
}

\author{
Amir Jafargholi and Manouchehr Kamyab \\ K. N. Toosi University of Technology \\ Iran
}

\section{Introduction}

The increasing demands on compact multifunctional devices have necessitated the development of multi-frequency printed dipoles which can be integrated into familiar devices such as laptop computers and mobile phones. The typical difficulties encountered in designing compact antennas include narrow bandwidth, and low radiation efficiency. In order to achieve a good efficiency, considerable effort must be expended on the matching network. Other researchers have found that the bandwidth of the dipole antenna can be enhanced by loading the antenna with parallel lumped element circuits (Rogers et al., 2003). Over the last decade, increasing demands for low profile multifunctional antennas have resulted in considerable interest by the electromagnetic research community in Metamaterials (MTMs). Due to unique electromagnetic properties, MTMs have been widely considered in monopole and dipole antennas to improve their performance (Erentok et al., 2005; Erentok et al., 2008; Liu et al., 2009; Jafargholi et al., 2010). The applications of Composite Right/Left Handed (CRLH) structures to load the printed dipole have been investigated both numerically (lizuka et al., 2006; lizuka et al., 2007; Borja et al., 2007) and analytically (Rafaei et al., 2010). However, main drawbacks of this method are low gain and low efficiency. The use of transmission-line based MTMs to realize a tri-band monopole antenna has been recently investigated in (Zhu et al., 2010). However, the cross polarization levels of the proposed antenna in (Zhu et al., 2010) are very high. It is also known that the antenna properties can be improved by covering the metal radiating parts or filling the antenna volume. For instance, the bandwidth of the microstrip patch antenna can be significantly improved by replacing the dielectric substrate with the magneto-dielectric one (Mosallaei et al., 2007). Recently, (Erentok et al., 2008) have considered the use of Double Negative (DNG) cover to match an electrically small electric dipole antenna to free space. The effect of complex material coverings on the bandwidth of the antennas has been also investigated in (Tretyakov et al., 2004).

In this section, first, the influence of the material inclusions on the input impedance of the loaded dipoles excited by a delta function is analytically investigated. Novel and accurate analytical expressions for the input impedance of the loaded dipoles are proposed based on the mode matching technique. The boundary conditions are also enforced to obtain several simultaneous equations for the discrete modal coefficients inside the radiating region. Study of the input impedance of the whole multilayered structure is accomplished by the cascade connection of mediums as characterized by their constitutive parameters. New and accurate analytical formulas for the loaded dipole antenna are derived and successfully validated 
through a proper comparison with the results obtained with the commercial software CST Microwave Studio.

Moreover, a compact multiband printed dipole antenna loaded with reactive elements is proposed. The reactive loading of the dipole is inspired by the Epsilon-Negative (ENG) and DNG- MTM inclusions, which enable the loaded dipole to operate in multiband. The reactive loads are realized by two rake-shaped split ring resonators (SRRs) facing each other. Investigations reveal that the loaded dipole radiates at two or three separated bands depending on symmetrical or asymmetrical loading and load locations. The new resonance frequencies are lower than the natural resonance frequency of the conventional half wavelength dipole. In this range of frequencies, the radiation efficiency of the composite antenna is high. In order to validate the simulation results, a prototype of the proposed printed dipole is fabricated and tested. The agreement between the simulated and measured results is quite good.

\section{Full-wave analysis of loaded dipole antennas using mode-matching theory}

In recent years, introducing MTMs opened the way for many researcher groups to enhance the antenna performances. Due to unique electromagnetic properties, MTMs have been widely considered in monopole and dipole antennas to improve their performance (Jafargholi et al., 2010). The problem of dielectric loaded wire antenna is heretofore analyzed using numerical methods, e.g., Method of Moment (MoM) (Shams et al., 2007), Finite Difference Time Domain (FDTD) (Beggs et al., 1993), and simulations based on commercial software (Kennedy et al., 2006). However, the analytical analysis of the dielectric loaded dipole antennas has not been reported in the literature.

The novelty of this section is to introduce a mode-matching analysis of a dipole antenna loaded with material inclusions. In this section, a theoretical formulation for a multiply dielectric loaded slotted spherical antenna is proposed based on the mode-matching method, to predict the behavior of the loaded dipole. It is worth noting that the radiation pattern of a finite length small angle biconical antenna differs only slightly from the pattern of a dipole (Kraus et al., 2002). Here, since the biconical antenna can be exactly analyzed and it also reduces, in the limiting case, to a cylindrical dipole antenna (Collin et al., 1969), this structure is considered for the analytical investigations. The obtained analytical formulas confirm the general conclusions recently presented in (Shams et al., 2007; Beggs et al., 1993), regarding the effect of material inclusions on the dipole antenna performance. It is demonstrated that the inclusion influence on the input impedance of a dipole is significant only for DNG-MTM inclusions.

\subsection{Field analysis}

Fig. 1(a) illustrates a slotted dielectric loaded hollow conducting sphere of radius $a$, containing a Hertzian dipole $\overline{\mathrm{J}}=\hat{\mathrm{z}} \mathrm{J} \delta\left(\overline{\mathrm{r}}-\overline{\mathrm{r}}^{\prime}\right)$, placed at the center $\left(\mathrm{r}=\mathrm{r}^{\prime}, \theta=0, \phi\right)$, Here $(\mathrm{r}, \theta, \phi)$ are the spherical coordinates and $\delta$ is a delta function. The time convention of is $\mathrm{e}^{-\mathrm{j} \omega \mathrm{t}}$ suppressed throughout. Due to azimuthally symmetry, the fields depend on $(\mathrm{r}, \theta)$ and the fields are then TM waves, which can be expressed in terms of magnetic vector potentials. The total magnetic vector potential for the un-slotted sphere (First region, I) is a sum of the primary and secondary magnetic vector potentials, (Ock et al., 2009). 


$$
\mathrm{A}^{\mathrm{i}}(\mathrm{r}, \theta)=\hat{\mathrm{z}} \mathrm{A}_{\mathrm{z}}^{\mathrm{p}}(\mathrm{r}, \theta)+\hat{\mathrm{r}} \mathrm{A}_{\mathrm{r}}^{\mathrm{s}}(\mathrm{r}, \theta)
$$

While, the primary magnetic vector potential is a free-space Green's function as

$$
\mathrm{A}_{\mathrm{z}}^{\mathrm{p}}(\mathrm{r}, \theta)=\frac{\mu_{1} \mathrm{~J}}{4 \pi} \frac{\mathrm{e}^{\mathrm{ik} \mathrm{k}_{1} \mathrm{R}}}{\mathrm{R}}
$$

where $\hat{z}$ and $\hat{r}$ are unit vectors and $\mathrm{R}=\sqrt{\mathrm{r}^{2}+\mathrm{r}^{\prime 2}-2 \mathrm{rr}^{\prime} \cos \theta}$. And the secondary magnetic vector potential is

$$
\mathrm{A}_{\mathrm{r}}^{\mathrm{s}}(\mathrm{r}, \theta)=\sum_{\mathrm{n}=0}^{\infty} \mathrm{a}_{\mathrm{n}} \hat{\mathrm{J}}_{\mathrm{n}}\left(\mathrm{k}_{\mathrm{I}} \mathrm{r}\right) \mathrm{P}_{\mathrm{n}}(\cos \theta)
$$

where $\hat{J}_{n}($.$) is the spherical Bessel function and P_{n}($.$) is the Legendre function. The$ coefficient is (Ock et al., 2009)

$$
\begin{aligned}
& \mathrm{a}_{\mathrm{n}}=\frac{\mu_{1} \mathrm{aJ}}{8 \pi \mathrm{k}_{1} \hat{J}_{\mathrm{n}}^{\prime}\left(\mathrm{k}_{1} \mathrm{a}\right)} \frac{2 \mathrm{n}+1}{\mathrm{n}(\mathrm{n}+1)} \int_{0}^{\pi} \Omega \frac{\partial \mathrm{P}_{\mathrm{n}}(\cos \theta)}{\partial \theta} \sin ^{2} \theta \mathrm{d} \theta \\
& \Omega=\left\{\left(\mathrm{a}^{2}-2 \mathrm{r}^{\prime 2}+\mathrm{ar}^{\prime} \cos \theta\right)\left(\mathrm{ik}_{1} \tilde{\mathrm{R}}-1\right)+\mathrm{k}_{1}^{2} \tilde{\mathrm{R}}^{2}\left(\mathrm{a}^{2}-\mathrm{ar}^{\prime} \cos \theta\right)\right\} \frac{\mathrm{e}^{\mathrm{ik}_{1} \tilde{\mathrm{R}}}}{\tilde{\mathrm{R}}^{5}}
\end{aligned}
$$

Now consider a slotted conducting sphere, as shown in Fig. 1(a). The total magnetic vector potential in region (I) consists of the incident $A^{i}$ and scattered $A_{r}^{I}$ potentials as

$$
A_{r}^{I}(r, \theta)=\sum_{n=0}^{\infty} C_{n} \hat{J}_{n}\left(k_{I} r\right) P_{n}(\cos \theta)
$$

Here, $C_{n}$ is an unknown modal coefficient. The $r$-component of the magnetic vector potential in region (II, III, IV, and V) of the $l$-th slot is

$$
\mathrm{A}_{\mathrm{r}}^{\gamma}(\mathrm{r}, \theta)=\sum_{\mathrm{v}=0}^{\infty} \mathrm{R}_{\mathrm{v}}^{\mathrm{l}, \gamma}(\cos \theta)\left[\mathrm{D}_{\mathrm{v}}^{\mathrm{l}, \gamma} \hat{\mathrm{J}}_{\xi_{\mathrm{v}}^{\mathrm{l}}}\left(\mathrm{k}_{\gamma} \mathrm{r}\right)+\mathrm{E}_{\mathrm{v}}^{\mathrm{l}, \gamma} \hat{\mathrm{N}}_{\xi_{\mathrm{v}}^{\mathrm{l}}}\left(\mathrm{k}_{\gamma} \mathrm{r}\right)\right], \quad \gamma=\mathrm{II}, \mathrm{III}, \mathrm{IV}, \mathrm{V}
$$

Where

$$
\mathrm{R}_{\mathrm{v}}^{1, \gamma}(\cos \theta)=\left\{\begin{array}{cc}
\mathrm{Q}_{\xi_{\mathrm{v}}}(\cos \theta) & \mathrm{v}=0 \\
\mathrm{Q}_{\xi_{\mathrm{v}}}\left(\cos \alpha_{2}^{1}\right) \mathrm{P}_{\xi_{\mathrm{v}}}(\cos \theta)-\mathrm{P}_{\xi_{\mathrm{v}}}\left(\cos \alpha_{2}^{1}\right) \mathrm{Q}_{\xi_{\mathrm{v}}}(\cos \theta) & \mathrm{v} \geq 1 \\
\mathrm{P}_{\xi_{\mathrm{v}}}(\cos \theta)+\mathrm{G}_{\xi_{\mathrm{v}}}^{\gamma} \mathrm{Q}_{\xi_{\mathrm{v}}}(\cos \theta) & \mathrm{II}, \mathrm{V} \\
& \mathrm{III}, \mathrm{IV}
\end{array}\right.
$$

The $r$-component of the magnetic vector potential in region (VI) is

$$
\mathrm{A}_{\mathrm{r}}^{\mathrm{VI}}(\mathrm{r}, \theta)=\sum_{\mathrm{v}=0}^{\infty} \mathrm{F}_{\mathrm{n}} \hat{\mathrm{H}}_{\mathrm{n}}^{(2)}\left(\mathrm{k}_{\mathrm{VI}} \mathrm{r}\right) \mathrm{P}_{\mathrm{n}}(\cos \theta)
$$




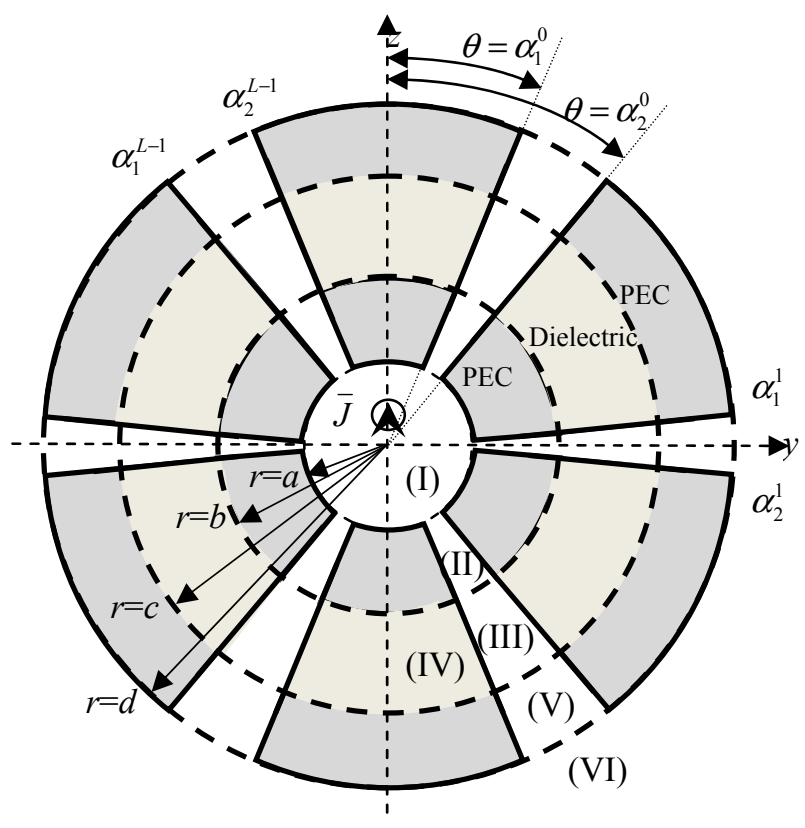

(a)

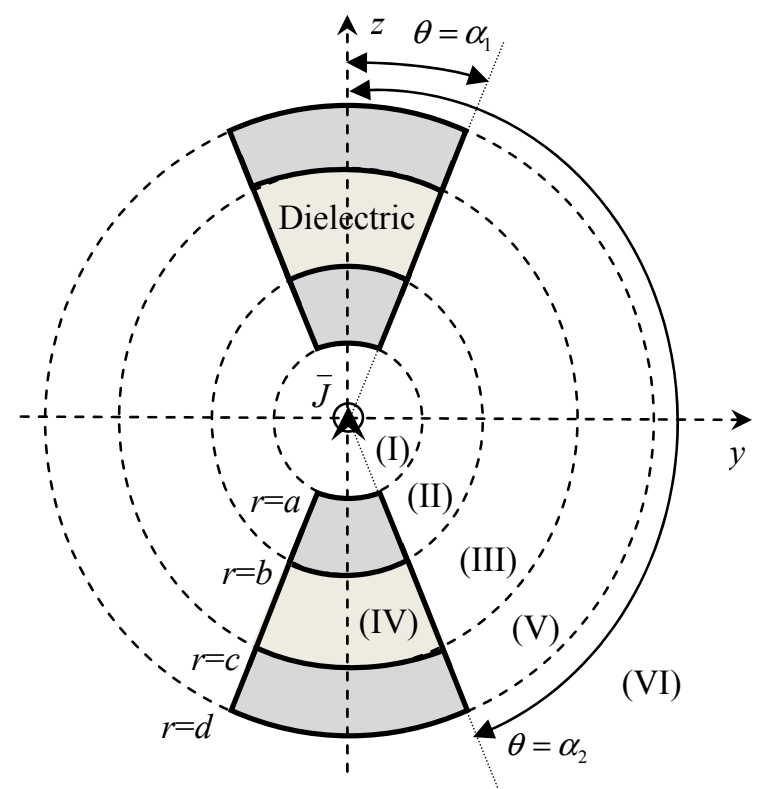

(b) 


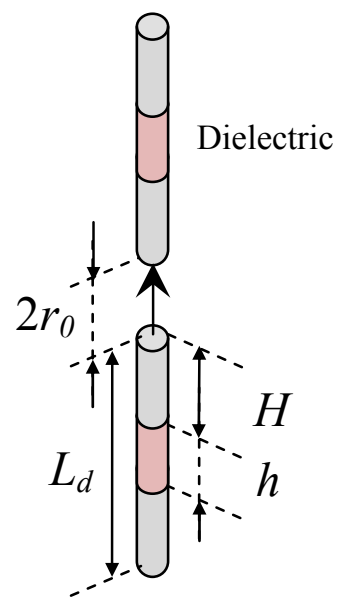

(c)

Fig. 1. (a) Multiply- (b) single slotted dielectric loaded conducting hollow sphere, and (c) dielectric loaded dipole antenna: cross-sectional view, $a=0.1 \mathrm{~mm}, b=2.5 \mathrm{~mm}$, $h=|c-b|=0.5 \mathrm{~mm}, d=5 \mathrm{~mm}, r_{0}=0.1 \mathrm{~mm}, H=2.4 \mathrm{~mm}, L_{d}=4.9 \mathrm{~mm}$, and the dipole radius, $r_{d}$, is equal to $0.1 \mathrm{~mm}$. From (Jafargholi et. al., 2012), copyright (C) 2012 by the Electromagnetics, Taylor \& Francis Group, LLC.

where $F_{n}$ is an unknown modal coefficient and $\hat{H}_{n}^{(2)}($.$) is the spherical Hankel function of the$ second kind. To determine the modal coefficients, we enforce the field continuities as Table 1.

\begin{tabular}{|l|l|l|l|l|}
\hline Boundary & layers & Electric Fields & Magnetic Fields & Limits \\
\hline 1 & I , II & $\mathrm{E}_{\theta}^{\mathrm{II}}=\left\{\begin{array}{cc}\mathrm{E}_{\theta}^{\mathrm{I}} & \alpha_{1}^{\mathrm{q}}<\theta<\alpha_{2}^{\mathrm{q}} \\
0 & \text { otherwise }\end{array}\right.$ & $\mathrm{H}_{\phi}^{\mathrm{i}}+\mathrm{H}_{\phi}^{\mathrm{I}}=\mathrm{H}_{\phi}^{\mathrm{II}}$ & $\begin{array}{l}r=a, \\
\alpha_{1}^{\mathrm{q}}<\theta<\alpha_{2}^{\mathrm{q}}\end{array}$ \\
\hline 2 & II , III & $\mathrm{E}_{\theta}^{\mathrm{III}}=\left\{\begin{array}{cc}\mathrm{E}_{\theta}^{\mathrm{II}} & \alpha_{1}^{\mathrm{q}}<\theta<\alpha_{2}^{\mathrm{q}} \\
0 & \text { otherwise }\end{array}\right.$ & $\mathrm{H}_{\phi}^{\mathrm{III}}=\mathrm{H}_{\phi}^{\mathrm{II}}$ & $\begin{array}{l}r=b, \\
\alpha_{1}^{\mathrm{q}}<\theta<\alpha_{2}^{\mathrm{q}}\end{array}$ \\
\hline 3 & III , V & $\mathrm{E}_{\theta}^{\mathrm{III}}=\left\{\begin{array}{cc}\mathrm{E}_{\theta}^{\mathrm{V}} & \alpha_{1}^{\mathrm{q}}<\theta<\alpha_{2}^{\mathrm{q}} \\
0 & \text { otherwise }\end{array}\right.$ & $\mathrm{H}_{\phi}^{\mathrm{III}}=\mathrm{H}_{\phi}^{\mathrm{V}}$ & $\begin{array}{l}r=c, \\
\alpha_{1}^{\mathrm{q}}<\theta<\alpha_{2}^{\mathrm{q}}\end{array}$ \\
\hline 5 & V, VI & $\mathrm{E}_{\theta}^{\mathrm{VI}}=\left\{\begin{array}{cc}\mathrm{E}_{\theta}^{\mathrm{V}} & \alpha_{1}^{\mathrm{q}}<\theta<\alpha_{2}^{\mathrm{q}} \\
0 & \text { otherwise }\end{array}\right.$ & $\mathrm{H}_{\phi}^{\mathrm{VI}}=\mathrm{H}_{\phi}^{\mathrm{V}}$ & $\begin{array}{l}r=d, \\
\alpha_{1}^{\mathrm{q}}<\theta<\alpha_{2}^{\mathrm{q}}\end{array}$ \\
\hline III , IV & $\mathrm{E}_{\mathrm{r}}^{\mathrm{IV}}=\mathrm{E}_{\mathrm{r}}^{\mathrm{III}}$ & $\mathrm{H}_{\phi}^{\mathrm{VI}}=\mathrm{H}_{\phi}^{\mathrm{III}}$ & $\begin{array}{l}b<r<c \\
\theta=\alpha_{1,2}^{\mathrm{q}}\end{array}$ \\
\hline
\end{tabular}

Table 1. Boundary conditions

Applying orthogonal integrals and mathematical manipulation some can write the equations as follow. 


$$
\begin{aligned}
& \mathrm{C}_{\mathrm{n}}=-\sqrt{\frac{\mu_{\mathrm{I}} \varepsilon_{\mathrm{I}}}{\mu_{\mathrm{II}} \varepsilon_{\mathrm{II}}}} \frac{2 \mathrm{n}+1}{2 \mathrm{n}(\mathrm{n}+1)} \frac{1}{\hat{\mathrm{J}}_{\mathrm{n}}^{\prime}\left(\mathrm{k}_{\mathrm{I}} \mathrm{a}\right)} \sum_{\mathrm{l}=0}^{\mathrm{L}-1} \sum_{\mathrm{v}=0}^{\infty}\left[\mathrm{D}_{\mathrm{v}}^{\mathrm{l}, \mathrm{II}} \hat{\mathrm{J}}_{\xi_{\mathrm{v}}}^{\prime}\left(\mathrm{k}_{\mathrm{II}} \mathrm{a}\right)+\mathrm{E}_{\mathrm{v}}^{\mathrm{l}, \mathrm{II}} \hat{\mathrm{N}}_{\xi_{\mathrm{v}}}^{\prime}\left(\mathrm{k}_{\mathrm{II}} \mathrm{a}\right)\right] \mathrm{I}_{\mathrm{vn}}^{\mathrm{l}, \mathrm{II}} \\
& \sum_{\mathrm{l}=0}^{\mathrm{L}-1} \sum_{\mathrm{v}=0}^{\infty}\left\{\mathrm{D}_{\mathrm{v}}^{\mathrm{l}, \mathrm{II}}\left[\hat{\mathrm{J}}_{\xi_{\mathrm{v}}}^{\prime}\left(\mathrm{k}_{\mathrm{II}} \mathrm{a}\right) X_{\mathrm{uv}}^{\mathrm{ql}}-\hat{\mathrm{J}}_{\xi_{\mathrm{v}}}\left(\mathrm{k}_{\mathrm{II}} \mathrm{a}\right) \mathrm{K}_{\mathrm{v}}^{1, \mathrm{II}} \delta_{\mathrm{ql}} \delta_{\mathrm{uv}}\right]+\mathrm{E}_{\mathrm{v}}^{\mathrm{l}, \mathrm{II}}\left[\hat{\mathrm{N}}_{\xi_{\mathrm{v}}}^{\prime}\left(\mathrm{k}_{\mathrm{II}} \mathrm{a}\right) X_{\mathrm{uv}}^{\mathrm{ql}}-\hat{\mathrm{N}}_{\xi_{\mathrm{v}}}\left(\mathrm{k}_{\mathrm{II}} \mathrm{a}\right) \mathrm{K}_{\mathrm{v}}^{1, \mathrm{II}} \delta_{\mathrm{ql}} \delta_{\mathrm{uv}}\right]\right\} \\
& =-\frac{\mu_{\mathrm{II}} \mathrm{Ja}^{2}}{4 \pi} \mathrm{L}_{\mathrm{u}}^{\mathrm{q}}+\frac{\mu_{\mathrm{II}}}{\mu_{\mathrm{I}}} \sum_{\mathrm{n}=0}^{\infty} \mathrm{a}_{\mathrm{n}} \hat{\mathrm{J}}_{\mathrm{n}}\left(\mathrm{k}_{\mathrm{I}} \mathrm{a}\right) \mathrm{I}_{\mathrm{un}}^{\mathrm{q}, \mathrm{II}} \\
& \sum_{\mathrm{l}=0}^{\mathrm{L}-1} \sum_{\mathrm{v}=0}^{\infty}\left[\mathrm{D}_{\mathrm{v}}^{1, \gamma} \hat{\mathrm{J}}_{\xi_{\mathrm{v}}^{\mathrm{v}}}^{\prime}\left(\mathrm{k}_{\gamma} \mathrm{r}\right)+\mathrm{E}_{\mathrm{v}}^{1, \gamma} \hat{\mathrm{N}}_{\xi_{\mathrm{v}}^{\mathrm{l}}}^{\prime}\left(\mathrm{k}_{\gamma} \mathrm{r}\right)\right] \mathrm{K}_{\mathrm{v}}^{1, \gamma} \\
& =\sqrt{\frac{\mu_{\gamma} \varepsilon_{\gamma}}{\mu_{\gamma^{\prime}} \varepsilon_{\gamma^{\prime}}}} \sum_{\mathrm{l}=0}^{\mathrm{L}-1} \sum_{\mathrm{v}^{\prime}=0}^{\infty}\left[\mathrm{D}_{\mathrm{v}^{\prime}}^{1, \gamma^{\prime}} \hat{\mathrm{J}}_{\xi_{\mathrm{v}^{\prime}}^{\prime}}^{\prime}\left(\mathrm{k}_{\gamma^{\prime}} \mathrm{r}\right)+\mathrm{E}_{\mathrm{v}^{\prime}}^{1, \gamma^{\prime}} \hat{\mathrm{N}}_{\xi_{\mathrm{v}^{\prime}}}^{\prime}\left(\mathrm{k}_{\gamma^{\prime}} \mathrm{r}\right)\right] \mathrm{K}_{\mathrm{v}^{\prime}}^{1,, \gamma^{\prime}} \quad \begin{array}{r}
\gamma=\mathrm{II}, \mathrm{V} \\
\gamma^{\prime}=\mathrm{III} \\
\mathrm{r}=\mathrm{b}, \mathrm{c}
\end{array} \\
& \sum_{\mathrm{l}=0}^{\mathrm{L}-1} \sum_{\mathrm{v}=0}^{\infty}\left[\mathrm{D}_{\mathrm{v}}^{\mathrm{l}, \gamma} \hat{\mathrm{J}}_{\xi_{\mathrm{v}}}\left(\mathrm{k}_{\gamma} \mathrm{r}\right)+\mathrm{E}_{\mathrm{v}}^{\mathrm{l}, \gamma} \hat{\mathrm{N}}_{\xi_{\mathrm{v}}}\left(\mathrm{k}_{\gamma} \mathrm{r}\right)\right] \mathrm{K}_{\mathrm{v}}^{\mathrm{l}, \gamma} \\
& =\frac{\mu_{\gamma}}{\mu_{\gamma^{\prime}}} \sum_{\mathrm{l}=0}^{\mathrm{L}-1} \sum_{\mathrm{v}^{\prime}=0}^{\infty}\left[\mathrm{D}_{\mathrm{v}^{\prime}}^{\mathrm{l}, \gamma^{\prime}} \hat{\mathrm{J}}_{\xi_{\mathrm{v}^{\prime}}}\left(\mathrm{k}_{\gamma^{\prime}} \mathrm{r}\right)+\mathrm{E}_{\mathrm{v}^{\prime}}^{\mathrm{l}, \gamma^{\prime}} \hat{\mathrm{N}}_{\xi_{\mathrm{v}^{\prime}}}\left(\mathrm{k}_{\gamma^{\prime}} \mathrm{r}\right)\right] \mathrm{K}_{\mathrm{v}^{\prime}}^{\mathrm{l}, \gamma^{\prime}} \quad \begin{array}{r}
\gamma=\mathrm{II}, \mathrm{V} \\
, \gamma=\mathrm{III} \\
\mathrm{r}=\mathrm{b}, \mathrm{c}
\end{array} \\
& \sum_{\mathrm{v}=0}^{\infty} \xi_{\mathrm{v}}^{1}\left(\xi_{\mathrm{v}}^{1}+1\right)\left[\mathrm{D}_{\mathrm{v}}^{1, \text { III }} \mathrm{U}_{\mathrm{v}}+\mathrm{E}_{\mathrm{v}}^{1, \mathrm{III}} \mathrm{U}_{\mathrm{vw}}\right] \mathrm{R}_{\mathrm{v}}^{1, \text { III }}\left(\cos \theta_{0}\right)= \\
& \frac{\mu_{\mathrm{III}} \varepsilon_{\mathrm{III}}}{\mu_{\mathrm{IV}} \varepsilon_{\mathrm{IV}}} \sum_{\mathrm{v}^{\prime}=0}^{\infty} \xi_{\mathrm{v}^{\prime}}^{1}\left(\xi_{\mathrm{v}^{\prime}}^{1}+1\right)\left[\mathrm{D}_{\mathrm{v}^{\prime}}^{1, \mathrm{IV}} \mathrm{U}_{\mathrm{v}^{\prime} \mathrm{v}}+\mathrm{E}_{\mathrm{v}^{\prime}}^{1, \mathrm{IV}} \mathrm{U}_{\mathrm{v}^{\prime} \mathrm{w}}\right] \mathrm{R}_{\mathrm{v}^{\prime}}^{1, \mathrm{IV}}\left(\cos \theta_{0}\right), \quad \theta_{0}=\alpha_{1}^{1}, \alpha_{2}^{1} \\
& \sum_{\mathrm{l}=0}^{\mathrm{L}-1} \sum_{\mathrm{v}=0}^{\infty}\left\{\mathrm{D}_{\mathrm{v}}^{\mathrm{l}, \mathrm{v}}\left[\hat{\mathrm{J}}_{\xi_{\mathrm{v}}^{\mathrm{l}}}^{\prime}\left(\mathrm{k}_{\mathrm{v}} \mathrm{d}\right) \Psi_{\mathrm{uv}}^{\mathrm{ql}}-\hat{\mathrm{J}}_{\xi_{\mathrm{v}}}\left(\mathrm{k}_{\mathrm{v}} \mathrm{d}\right) \mathrm{K}_{\mathrm{v}}^{\mathrm{l}, \mathrm{v}} \delta_{\mathrm{ql}} \delta_{\mathrm{uv}}\right]+\mathrm{E}_{\mathrm{v}}^{\mathrm{l}, \mathrm{v}}\left[\hat{\mathrm{N}}_{\xi_{\mathrm{v}}}^{\prime}\left(\mathrm{k}_{\mathrm{v}} \mathrm{d}\right) \Psi_{\mathrm{uv}}^{\mathrm{ql}}-\hat{\mathrm{N}}_{\xi_{\mathrm{v}}}\left(\mathrm{k}_{\mathrm{v}} \mathrm{d}\right) \mathrm{K}_{\mathrm{v}}^{\mathrm{l}, \mathrm{v}} \delta_{\mathrm{ql}} \delta_{\mathrm{uv}}\right]\right\}=0 \\
& \mathrm{~F}_{\mathrm{n}}=-\sqrt{\frac{\mu_{\mathrm{VI}} \varepsilon_{\mathrm{VI}}}{\mu_{\mathrm{v}} \varepsilon_{\mathrm{V}}}} \frac{2 \mathrm{n}+1}{2 \mathrm{n}(\mathrm{n}+1)} \frac{1}{\hat{\mathrm{H}}_{\mathrm{n}}^{(1)}\left(\mathrm{k}_{\mathrm{vI}} \mathrm{d}\right)} \sum_{\mathrm{l}=0}^{\mathrm{L}-1} \sum_{\mathrm{v}=0}^{\infty}\left[\mathrm{D}_{\mathrm{v}}^{1, \mathrm{v}} \hat{\mathrm{J}}_{\xi_{\mathrm{v}}}^{\prime}\left(\mathrm{k}_{\mathrm{v}} \mathrm{d}\right)+\mathrm{E}_{\mathrm{v}}^{1, \mathrm{~V}} \hat{\mathrm{N}}_{\xi_{\mathrm{v}}}^{\prime}\left(\mathrm{k}_{\mathrm{v}} \mathrm{d}\right)\right] \mathrm{I}_{\mathrm{vn}}^{1, \mathrm{~V}}
\end{aligned}
$$

The required definitions are illustrated in the appendix. For a single slot configuration (biconical antenna loaded with a dielectric, Fig. 1(b), due to the magnetic field boundary condition between region III and IV, $\mathrm{R}_{\mathrm{v}}^{1, \gamma}(\cos \theta)$ has been simplified as

$$
\mathrm{R}_{\mathrm{v}}^{1, \gamma}(\cos \theta)=\left\{\begin{array}{cc}
\left\{\begin{array}{cc}
\mathrm{Q}_{\mathrm{v}}(\cos \theta) & \mathrm{v}=0 \\
\mathrm{Q}_{\mathrm{v}}\left(\cos \alpha_{2}\right) \mathrm{P}_{\mathrm{v}}(\cos \theta)-\mathrm{P}_{\mathrm{v}}\left(\cos \alpha_{2}\right) \mathrm{Q}_{\mathrm{v}}(\cos \theta) & \mathrm{v} \geq 1
\end{array}\right. & \mathrm{II}, \mathrm{V} \\
\mathrm{P}_{\mathrm{v}}(\cos \theta)+\left(\frac{\mu_{\mathrm{III}}}{\mu_{\mathrm{IV}}}-1\right)\left[\frac{\mathrm{P}_{\mathrm{v}}^{\prime}\left(\cos \alpha_{1}\right)-\mathrm{P}_{\mathrm{v}}^{\prime}\left(\cos \alpha_{2}\right)}{\mathrm{Q}_{\mathrm{v}}^{\prime}\left(\cos \alpha_{1}\right)-\mathrm{Q}_{\mathrm{v}}^{\prime}\left(\cos \alpha_{2}\right)}\right] \mathrm{Q}_{\mathrm{v}}(\cos \theta) & \mathrm{III} \\
\mathrm{P}_{\mathrm{v}}(\cos \theta) & \mathrm{IV}
\end{array}\right.
$$


Finally, the unknown coefficients are

$$
C_{n}, D_{v}^{I I}, E_{v}^{I I}, D_{v}^{I I I}, E_{v}^{I I I}, D_{v}^{I V}, E_{v}^{I V}, D_{v}^{V}, E_{v}^{V}, F_{n}
$$

\subsection{Numerical analysis}

From the formulas presented in the previous section it is straightforward to write short programs that illustrate the difference between the different types of material inclusions. To this aim, the cone angle of the biconical antenna is selected to be as small as possible, e.g., $2 a_{1}=2.5$ degree. To clear this selection, it is should be noted that, based on (Collin et al., 1969), it is well known that the input impedance of a biconical antenna changes significantly by changing cone angle. Hence the input impedance of a biconical antenna is investigated with regards to its cone angle. The inverse radiation impedance $Z_{v}$ of biconical antennas, for the small feed gap condition $\left(\mathrm{k}_{1} \mathrm{a}<<1\right)$ is given by (Ock et al., 2009; Saoudy et al., 1990)

$$
\mathrm{Z}_{\mathrm{v}}=\frac{\left.\mathrm{j} \eta_{2} \sin \alpha_{1} \ln \left(\cot \frac{\alpha_{1}}{2}\right) \sum_{\mathrm{v}=0}^{\infty}\left[\mathrm{D}_{\mathrm{v}}^{\mathrm{II}} \hat{\mathrm{j}}_{\xi_{\mathrm{v}}}\left(\mathrm{k}_{\mathrm{II}} \mathrm{b}\right)+\mathrm{E}_{\mathrm{v}}^{\mathrm{II}} \hat{\mathrm{N}}_{\xi_{\mathrm{v}}}\left(\mathrm{k}_{\mathrm{II}} \mathrm{b}\right)\right] \frac{\partial \mathrm{R}_{\xi_{\mathrm{v}}}(\cos \theta)}{\partial \theta}\right|_{\theta=\alpha_{1}}}{\pi\left[\mathrm{D}_{0}^{\mathrm{II}} \hat{j}_{0}^{\prime}\left(\mathrm{k}_{\mathrm{II}} \mathrm{b}\right)+\mathrm{E}_{0}^{\mathrm{II}} \hat{\mathrm{N}}_{0}^{\prime}\left(\mathrm{k}_{\mathrm{II}} \mathrm{b}\right)\right]}
$$

The analytic simulations have been compared with CST simulation results of an equivalent dipole antenna (radius, $r_{d}$ ). The results have been presented in Fig. 2. According to these results for the antenna radius $r_{d}<0.01 \lambda$ ( $\approx$ biconical antenna $2 a_{1} \leq 3.4$ degree, with regards to $f=25 \mathrm{GHz}$ as main frequency) the loaded dipole may be considered as a limit case of a loaded biconical antenna (the approximation meet numerical simulations with good agreement). The simulation parameters have been considered as: $a=0.1 \mathrm{~mm}, b=2.5 \mathrm{~mm}, h=|c-b|=0.5 \mathrm{~mm}$, $d=5 \mathrm{~mm}, r_{0}=0.1 \mathrm{~mm}, H=2.4 \mathrm{~mm}, L_{d}=4.9 \mathrm{~mm}$, and the dipole antenna filled with DPS material inclusions, $\left(\varepsilon_{r}=2.2\right.$ and $\left.\mu_{r}=1\right)$. It is should be noted that for the radius $0.01 \lambda<r_{d}<0.02 \lambda$, the antenna input impedance has been extracted approximately; and larger values cause significant errors in impedance computations.

\section{a. Dielectric-Covered Biconical Antennas}

To validate the proposed method, it is useful to consider a conventional covered biconical antenna (Fig. 3) as first limiting case. The input impedance of a thin biconical antenna embedded in dielectric material has been derived by (Tai et al., 1958). A slightly more general expression applicable to a biconical antenna embedded in a lossless material of arbitrary permeability and permittivity has been given by (Polk et al., 1959). Assuming $\mathrm{L}=1$, the region III fills by PEC, and $\mathrm{k}_{1} \mathrm{a}<<1$; the slotted conducting sphere becomes a biconical antenna, as shown in Fig. 3. In Fig. 4, the effects of the numbers of modes in computation convergence have been depicted. It is clear that good convergence has been achieved.

In Fig. 5, the analytic results for the impedance of a biconical antenna have been compared with CST simulation results. As it is stated before, the antenna cone angle has been chosen as $2 a_{1}=2.5$ degree. According to this figure, a good agreement has been achieved between analytic and numeric simulations. 


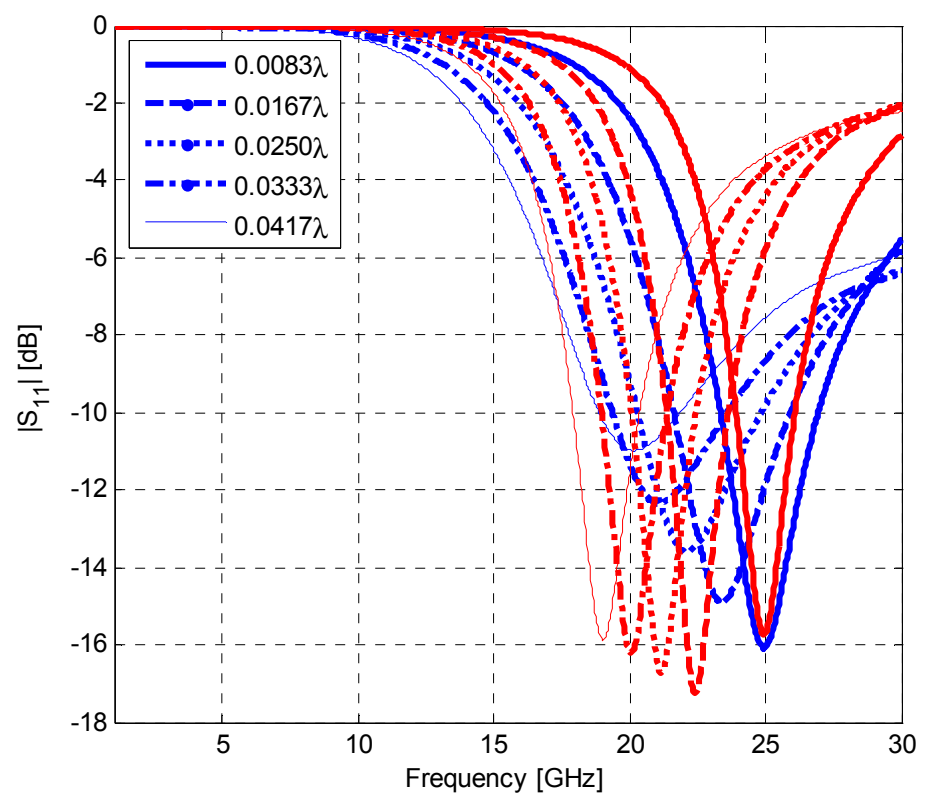

Fig. 2. The $\left|\mathrm{S}_{11}\right|[\mathrm{dB}]$ for a DPS-loaded dipole antenna: analytical (Blue) against numerical results (Red). Analytical results are obtained using proposed analytical expressions; while the numerical results are extracted using CST software. From (Jafargholi et. al., 2012), copyright (C) 2012 by the Electromagnetics, Taylor \& Francis Group, LLC.

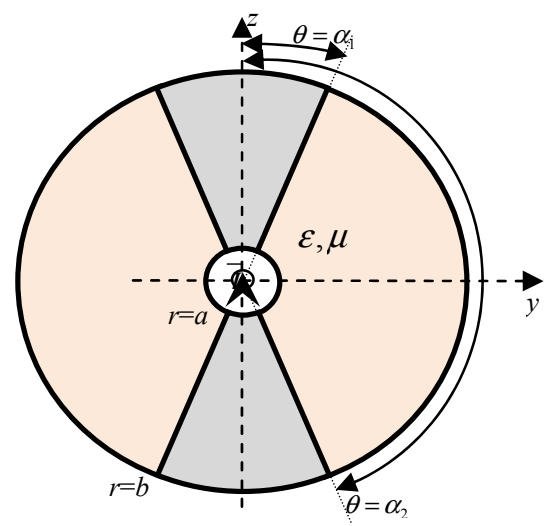

Fig. 3. Dielectric-covered biconical antenna: cross-sectional view, $a=0.1 \mathrm{~mm}, b=5 \mathrm{~mm}$, $\varepsilon_{r}=\mu_{r}=1$. From (Jafargholi et. al., 2012), copyright (C) 2012 by the Electromagnetics, Taylor \& Francis Group, LLC. 


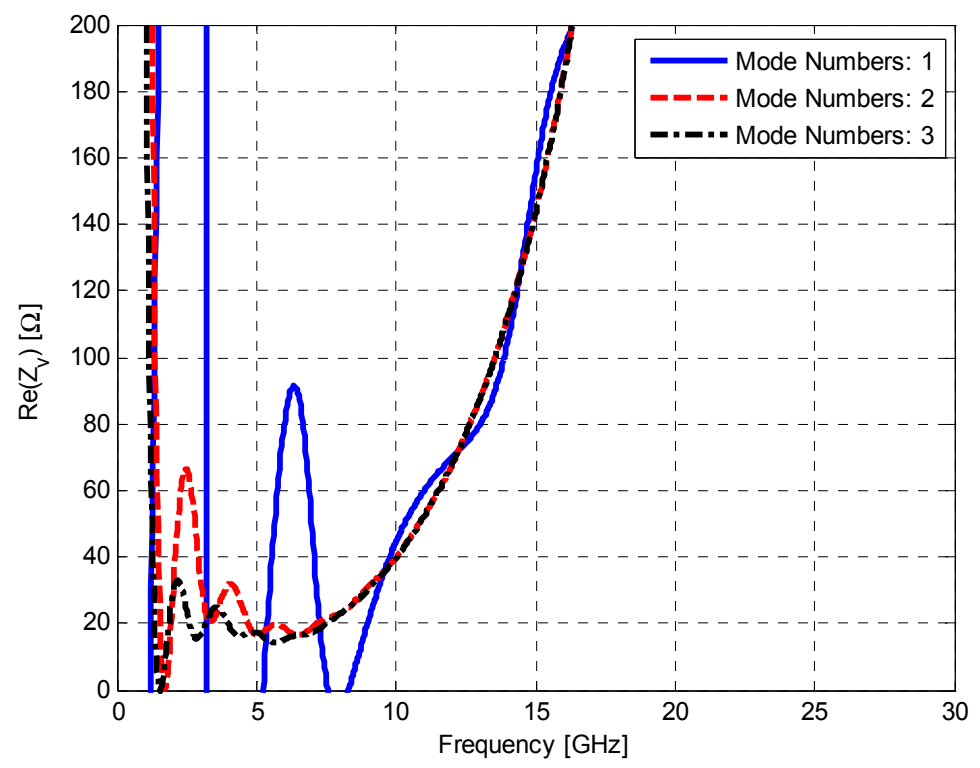

(a)

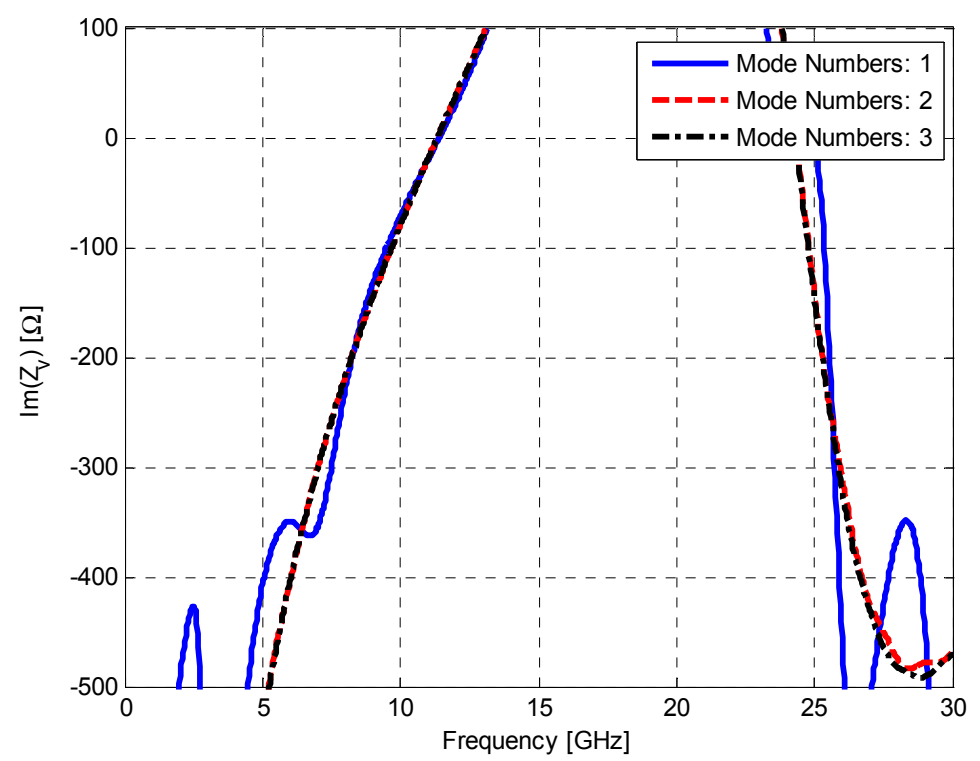

(b)

Fig. 4. Convergence analysis of the dielectric- covered biconical antenna, input impedance (a) real, and (b) imaginary parts. From (Jafargholi et. al., 2012), copyright (C) 2012 by the Electromagnetics, Taylor \& Francis Group, LLC. 


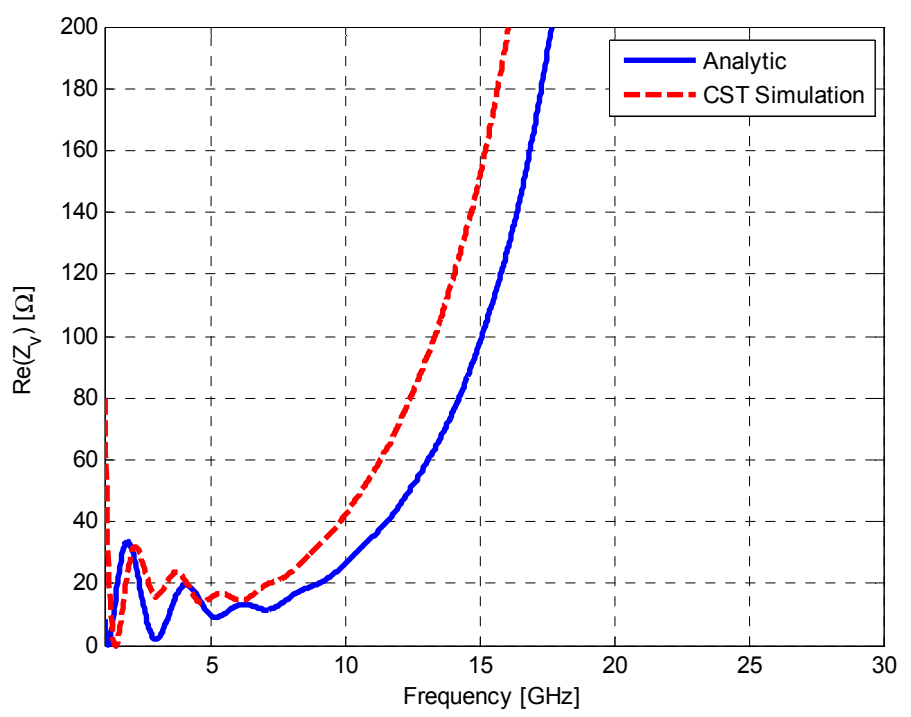

(a)

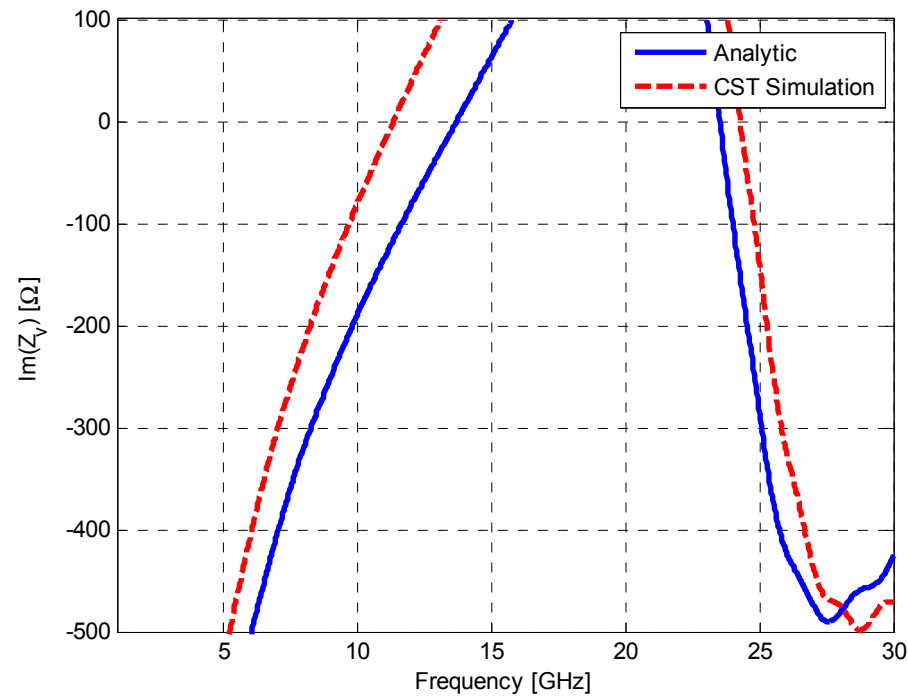

(b)

Fig. 5. Input impedance of the dielectric-covered biconical antenna: analytical against numerical results. Analytical results are obtained using proposed analytical expressions; numerical results are computed by CST software; (a) real, and (b) imaginary parts. From (Jafargholi et. al., 2012), copyright (C) 2012 by the Electromagnetics, Taylor \& Francis Group, LLC.

In Fig. 6, the analytic result for impedance of dielectric covered biconical antenna versus dielectric material has been illustrated. The antennas parameters are $b=5 \mathrm{~mm}, 2 a_{1}=2.5$ degree, 


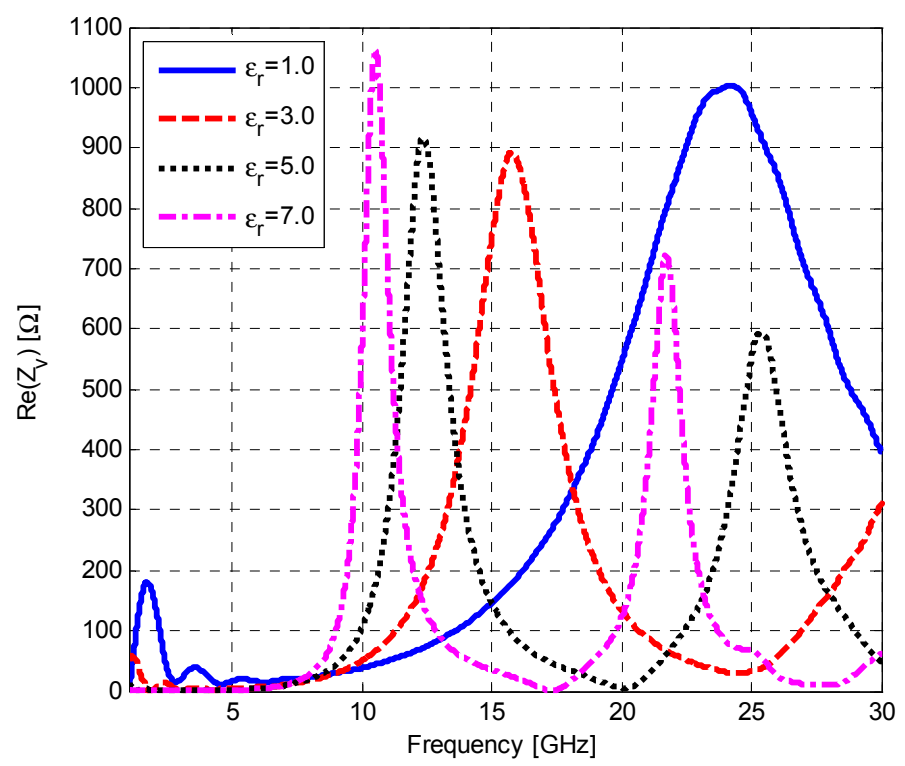

(a)

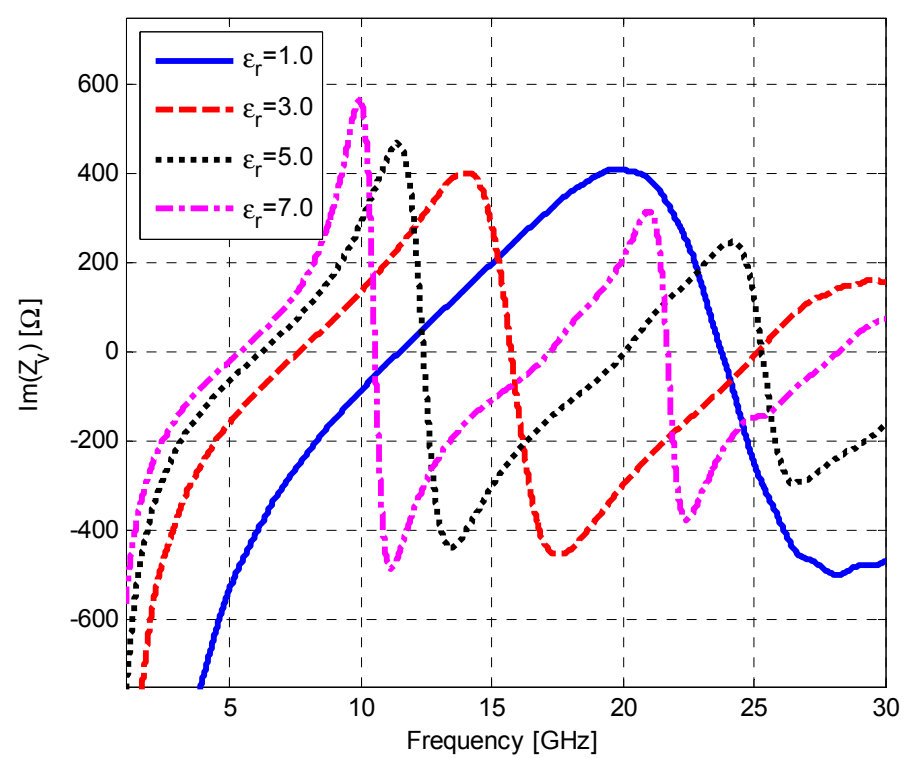

(b)

Fig. 6. Input impedance of the dielectric-loaded biconical antenna: analytical against numerical results. Analytical results are obtained using proposed analytical expressions; numerical results are computed by CST software; (a) real, and (b) imaginary parts. From (Jafargholi et. al., 2012), copyright (c) 2012 by the Electromagnetics, Taylor \& Francis Group, LLC. 
$a=0.1 \mathrm{~mm}$. It seems clearly that the antenna input impedance affects significantly with dielectric material. The insertion of dielectric material into the biconical antenna structure causes increased frequency dependence of the antenna. The larger material permittivity, the more rapid is the variation of the input impedance. Similar results have been obtained by (Saoudy et al., 1990; Tai et al., 1958; Polk et al., 1959).

\section{b. Dielectric Loaded Biconical Antenna}

In order to demonstrate the capability of the MTM loading to realize a miniaturized antenna, two examples are studied here. The first one is a dipole antenna filled with Double Positive (DPS) material inclusions, $\left(\varepsilon_{r}=2.2\right.$ and $\left.\mu_{r}=1\right)$. A DNG-loaded dipole antenna, whose parameters are labeled in Fig. 1(c), is also studied. Here, the Drude model (Jafargholi et al., 2011) is used to simulate the MTM inclusions, since it can yield a negative real part of the permittivity/permeability over a wide frequency range. For the DNG inclusions, both $\mu$ and $\varepsilon$ obey the Drude model (with plasma frequency $\omega_{\mathrm{p}}=15 \times 10^{10} \mathrm{rad} / \mathrm{s}$ and collision frequency $f_{\mathrm{c}}=0.01 \mathrm{GHz}$ ) as bellow

$$
\xi_{\mathrm{r}}(\omega)=\xi_{\infty}-\frac{\omega_{\mathrm{p}}^{2}}{\omega\left(\omega-\mathrm{iv}_{\mathrm{c}}\right)} \quad \xi \in\{\varepsilon, \mu\}
$$

In Fig. 7, the effects of the numbers of modes in computation convergence have been presented. Again, it is clear that good convergence has been obtained. The computation time of the analytic model is about 5 minutes for all frequency points compared to several hours using CST over a frequency range of 0 to $30 \mathrm{GHz}$, while this time increased in CST for higher permittivity and permeability materials. (For a 3.2GHz dual core CPU with 2GByte RAM).

The analytical results for the input impedance (both real and imaginary parts) of the DPSand DNG-loaded dipole antennas are presented in Fig. 8. As a reference, the simulated input impedance of equivalent DPS- and DNG- loaded dipoles are also plotted in this figure. As can be seen in this figure, the analytical results for the input impedance of the loaded dipoles are in good agreement with the CST simulation results. Simulations show that for the dipole antenna loaded with DNG-inclusions, an additional resonance frequency is introduced at the frequencies lower than the antenna resonant frequency where the antenna radiates an omnidirectional radiation pattern. In contrast, for the dipoles loaded with DPS-inclusions, changing DPS locations on the antenna arms causes no resonances at frequencies lower than the main resonant frequency.

\section{A compact multi-band printed dipole antenna loaded with single-cell MTM}

Now, the effect of material inclusions embedded in a simple dipole antenna has been investigated. The numerical investigations result in some general conclusions regarding the effect of material inclusions on the dipole antenna performance. It is demonstrated that in contrast to the DPS and Mu-Negative (MNG) MTMs, ENG- and DNG-MTM inclusions can provide multi-band performance. To practically realize this method, a compact multiband printed dipole antenna is designed using reactive loading, which is inspired by ENG-MTM inclusions. To this aim, a novel printed MTM element is proposed and successfully tested. The proposed MTM cell shows ENG behavior at around the antenna operating frequency. 


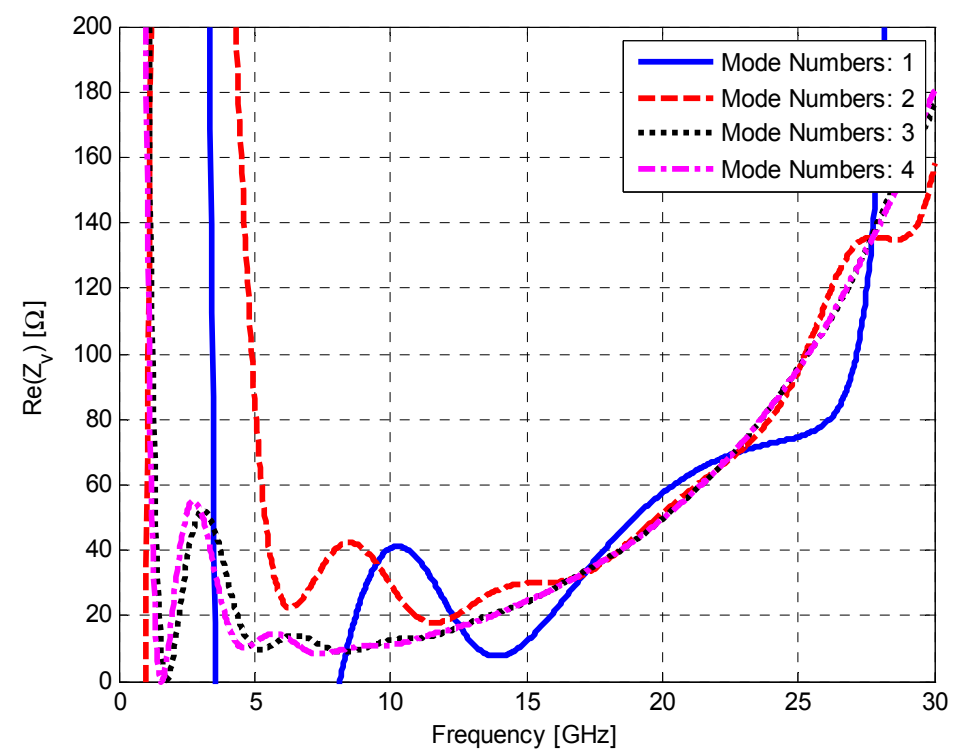

(a)

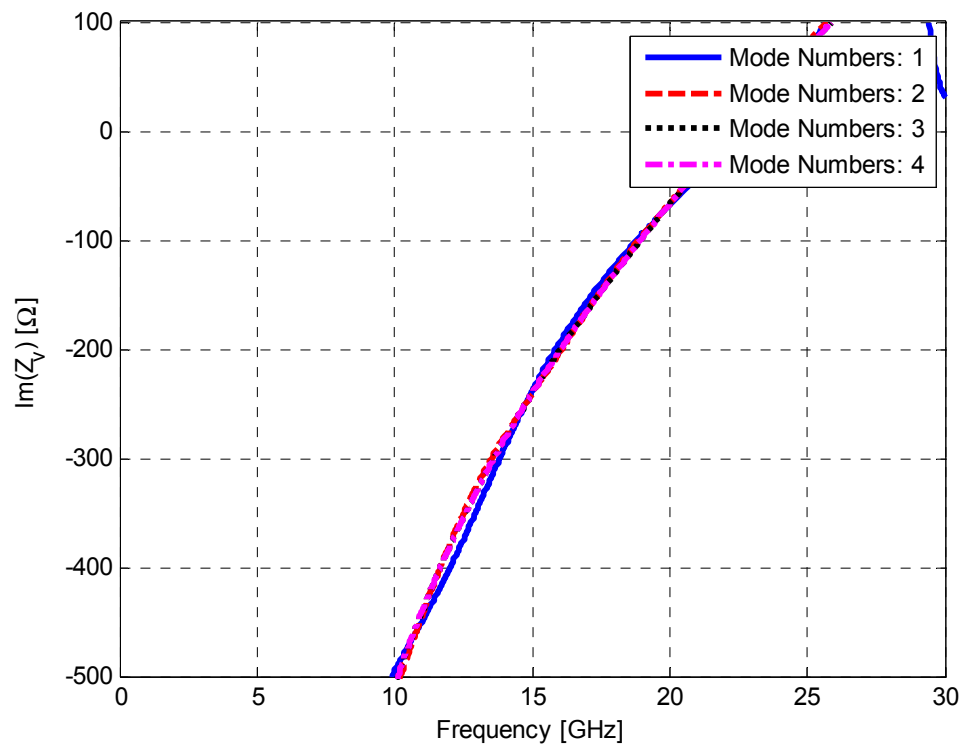

(b)

Fig. 7. Convergence analysis of the dielectric- loaded biconical antenna, input impedance (a) real, and (b) imaginary parts. From (Jafargholi et. al., 2012), copyright (C) 2012 by the Electromagnetics, Taylor \& Francis Group, LLC. 


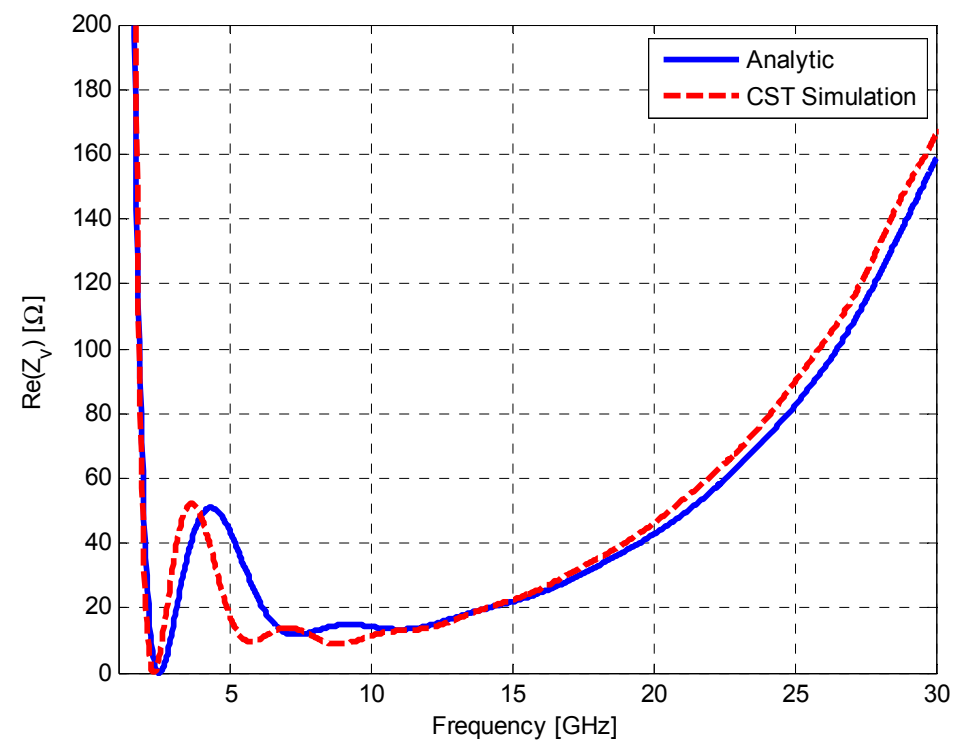

(a)

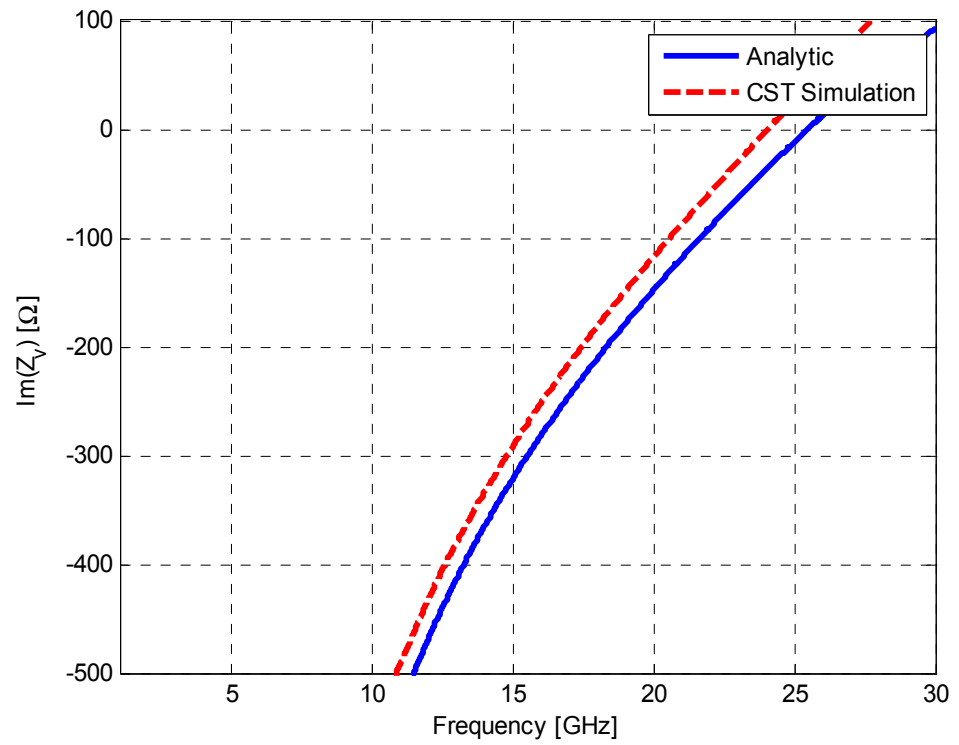

(b) 


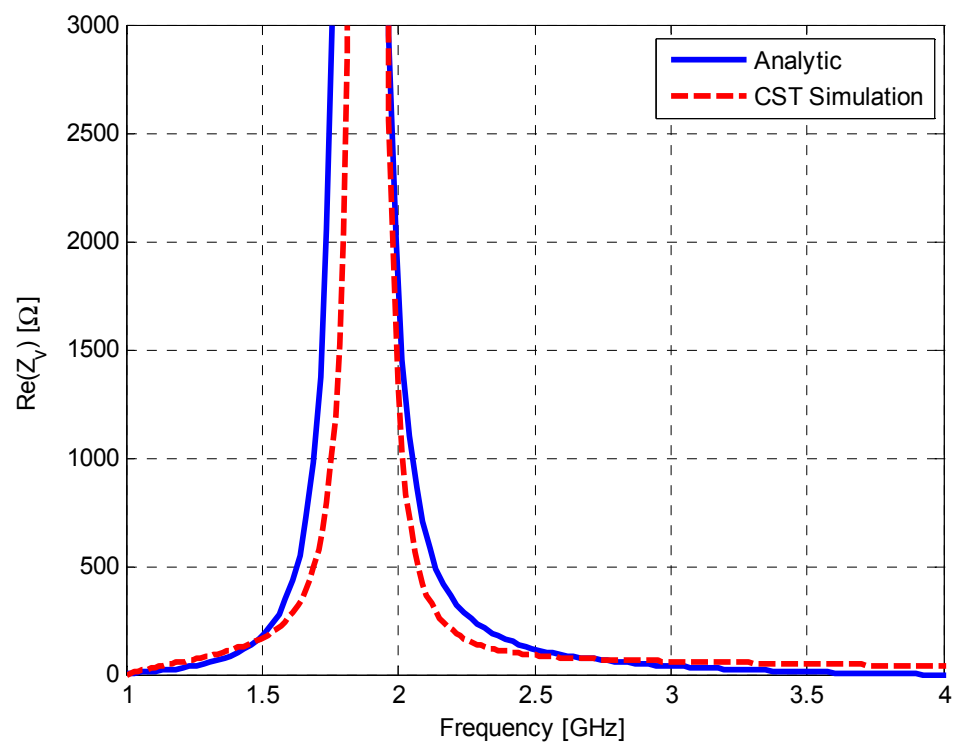

(c)

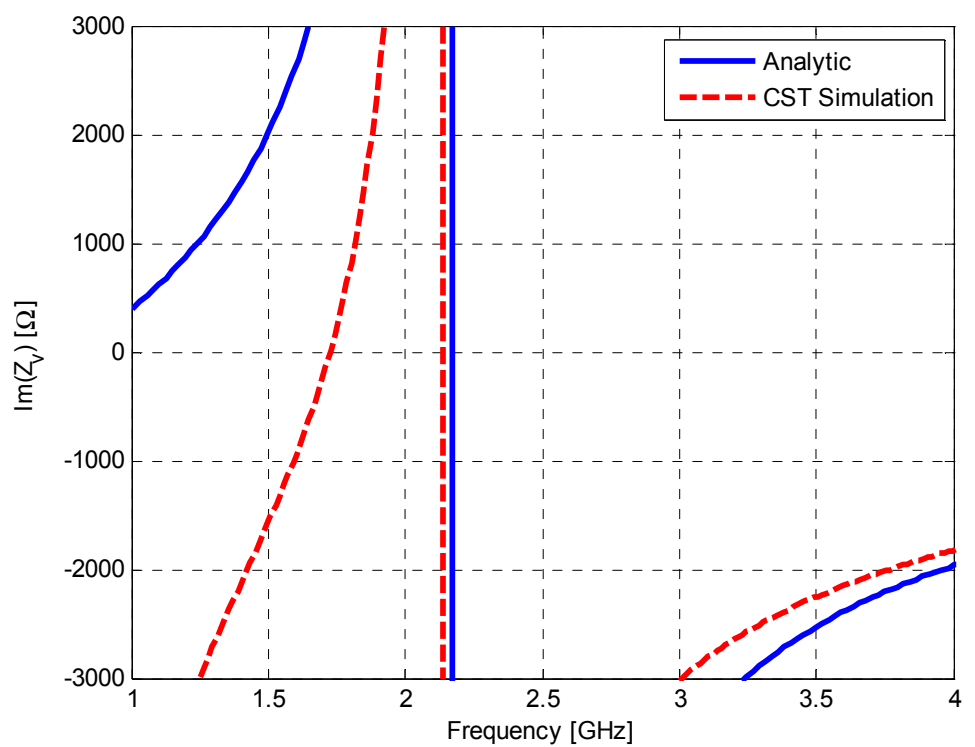

(d)

Fig. 8. Input impedance of the loaded biconical antenna: analytical against numerical results. Analytical results are obtained using proposed analytical expressions; numerical results are computed by CST software; (a) real, and (b) imaginary parts for dielectric materials and (c) real, and (d) imaginary parts for DNG metamaterials. From (Jafargholi et. al., 2012), copyright (C) 2012 by the Electromagnetics, Taylor \& Francis Group, LLC. 
The dimensions of the proposed MTM cell is optimized to meet the specifications of the mobile bands $(890.2 \mathrm{MHz}-914.8 \mathrm{MHz}$, and $1710 \mathrm{MHz}-1784 \mathrm{MHz})$ while maintaining its compact size. The antenna radiation efficiency at the first resonance frequency is significantly higher than those reported for other miniaturized printed dipoles in the literature (Iizuka et al., 2006; lizuka et al., 2007; Borja et al., 2007; Rafaei et al., 2010). It is worthwhile to point out here that the subject of single-cell MTM loading is not new and has been studied by other authors (Zhu et al., 2010).

\subsection{A dipole antenna loaded with MTM inclusion}

It is known that the resonance frequencies of an original monopole/dipole are harmonics of the main resonant frequency $\omega_{1}$. However, ominidirectional radiation pattern distortion and low directivity are two major disadvantages associated with monopole/dipole antenna resonating at higher order harmonics $\left(\omega_{m}>\omega_{1}\right)$ (Balanis, 1989; Jafargholi et al., 2010).

In this section, a simple and intuitive rule for determining the beneficial filling material type for dipole antennas has been introduced. A dipole antenna loaded with cylindrical dispersive MTM inclusions is shown in Fig. 9. It is assumed that the MTM inclusions are embedded in the both arms of the dipole. Here, the Drude model (Engheta et al., 2006) is used to simulate the MTM inclusions, since it can yield a negative real part of the permittivity/permeability over a wide frequency range. Depending on the MTM type either $\mu$ or $\varepsilon$ (or both) obey the Drude model (with plasma frequency $\omega_{p}=1.8 \times 10^{10} \mathrm{rad} / \mathrm{s}$ and collision frequency $f_{\mathrm{c}}=0.2 \mathrm{GHz}$ ) and are equal to one otherwise. The distance from the location of the MTM inclusions to the feed point is denoted as $d_{\text {MIF }}$.

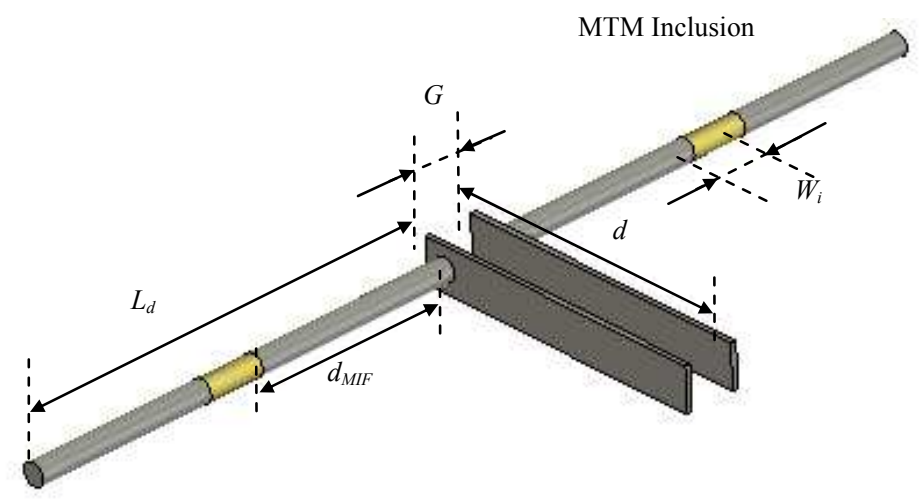

Fig. 9. An ideal model of MTM loaded dipole: $L_{d}=120 \mathrm{~mm}, W_{i}=2.5 \mathrm{~mm}, G=5 \mathrm{~mm}, d=27 \mathrm{~mm}$. From (Rafaei et al., 2011), copyright (C) 2011 by the IET Microwaves, Antennas \& Propagation.

The behaviors of the loaded dipole as a function of the MTM type and the distance of the MTM inclusions from the antenna feed point, $d_{\text {MIF }}$, have been studied. Fig. 10 shows the antenna reflection coefficient for the dipoles loaded with DPS-, MNG-, DNG-, and ENGinclusions, with $d_{M I F}$ as a parameter. As the ENG- or DNG- inclusions are added, the antenna resonant behavior changes. 
It can be concluded from Fig. 10 that for the dipole antenna loaded with DNG- or ENGinclusions, an additional resonance frequency is introduced at the frequencies lower than the antenna resonant frequency where the antenna radiates an omnidirectional radiation pattern. In contrast, for the dipoles loaded with DPS- or MNG-inclusions, changing DPS/MNG locations on the antenna arms causes no resonances at frequencies lower than the main resonant frequency, as shown in Fig. 10(a,b).

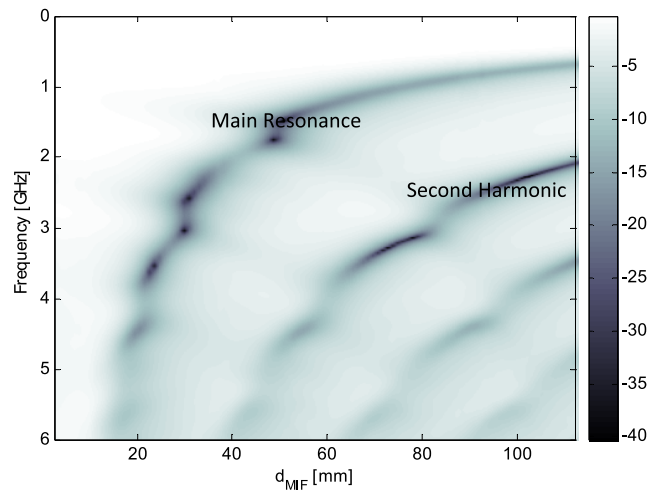

(a)

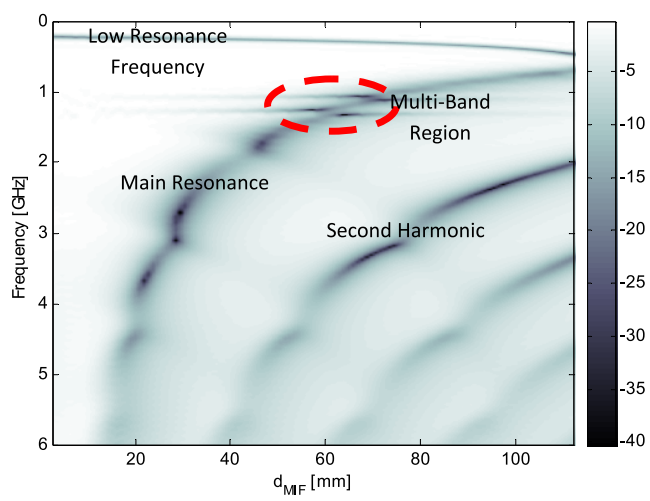

(c)

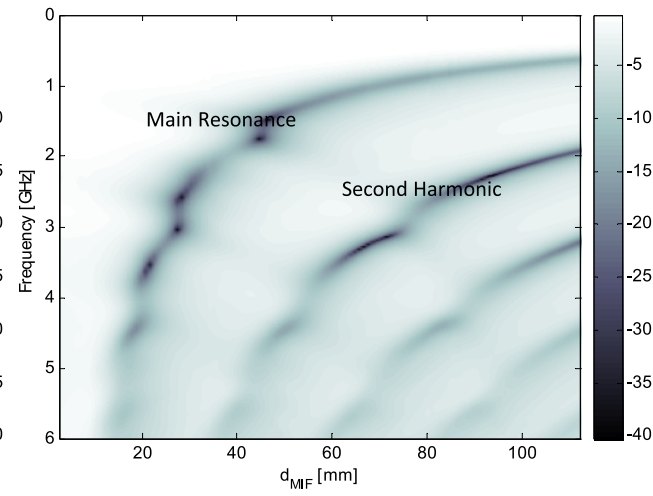

(b)

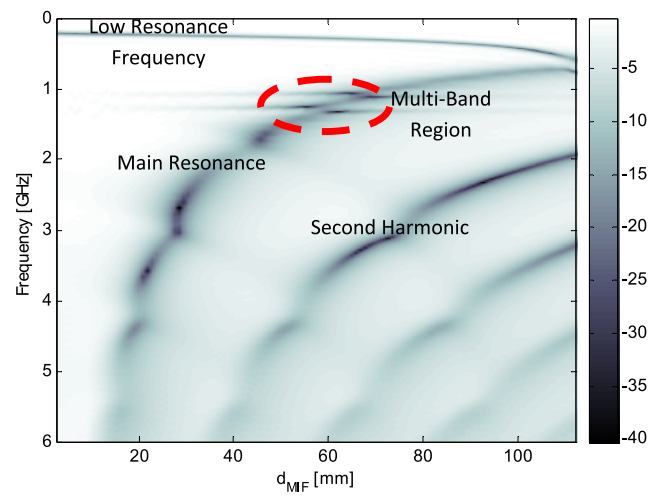

(d)

Fig. 10. CST simulation results for $\left|S_{11}\right|[d B]$, versus location of (a) DPS-, (b) MNG-, (c) DNG- and (d) ENG-inclusions. From (Rafaei et al., 2011), copyright (C) 2011 by the IET Microwaves, Antennas \& Propagation.

As the distance between the ENG-/DNG-inclusions and the feed point is increased, the main resonant frequency decreases while the low resonant frequency is almost unchanged. This feature provides the ability to choose the second resonance frequency arbitrarily based on provision dictated by application. And thus the frequency ratio between these two frequencies can be readily controlled by adjusting the inclusion locations. 
In addition, for the case of the dipoles loaded with DNG-/ENG-blocks and $50 \mathrm{~mm}<d_{M I F}<75 \mathrm{~mm}$, more than one resonance is introduced at around the antenna main resonant frequency where the antenna radiates omnidirectional radiation patterns, as shown in Fig. 10(c,d).

To make the concept more clear, three DNG loaded dipoles are designed and simulated. The reflection coefficient results for the dipole antennas loaded with different DNG blocks and different $d_{M I F}$ are shown in Fig. 11. For comparison purposes, the reflection coefficient of an unloaded dipole antenna is also presented in Fig. 11. As can be seen, all the antennas have multi-resonance behavior. The first frequency bands of the proposed loaded dipoles are narrow. This narrow frequency bands are the direct consequence of the resonant nature of the MTM inclusions. The gain, efficiency, and bandwidth of the three loaded dipoles are compared in Table 2. For the first design, the antenna bandwidth at first resonance is quite good but its gain is low. In contrast, for the second design, the antenna has a high gain at the first resonance frequency but at the expense of a narrower bandwidth. As a result, the type of the DNG-inclusion is a result of a trade-off between the antenna radiation efficiency (gain) and bandwidth, such as design III.

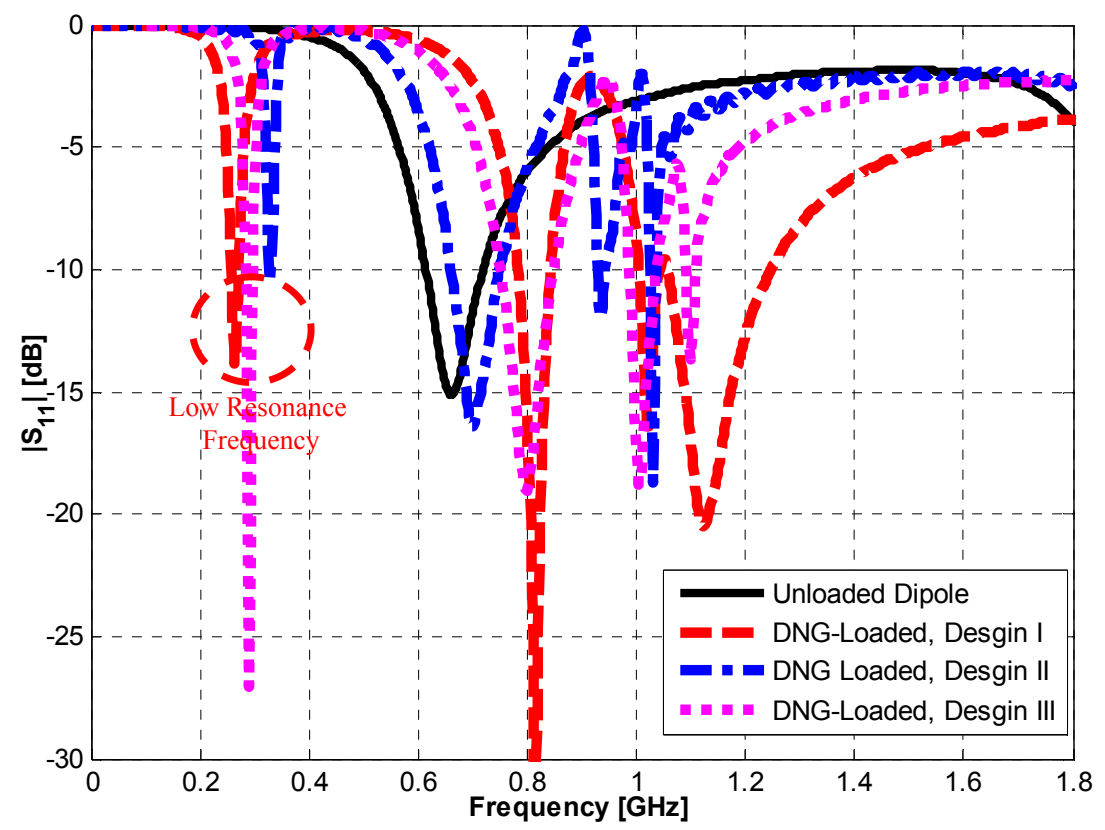

Fig. 11. Reflection coefficient results for dipole antennas loaded with different DNG blocks; Design I: $d_{M I F}=72 \mathrm{~mm}$ and Drude model with $\omega_{p}=1.8 \times 10^{10} \mathrm{rad} / \mathrm{s}$, and $f_{\mathcal{C}}=0.2 \mathrm{GHz}$, Design II: $d_{M I F}=100 \mathrm{~mm}, \omega_{p}=1.8 \times 10^{10} \mathrm{rad} / \mathrm{s}$ and $f_{c}=0.01 \mathrm{GHz}$, and Design III: $d_{M I F}=85 \mathrm{~mm}, \omega_{p}=1.8 \times 10^{10} \mathrm{rad} / \mathrm{s}$ and $f_{c}=0.1 \mathrm{GHz}$. As a reference, an unloaded dipole antenna is also simulated. From (Rafaei et al., 2011), copyright (C 2011 by the IET Microwaves, Antennas \& Propagation. 


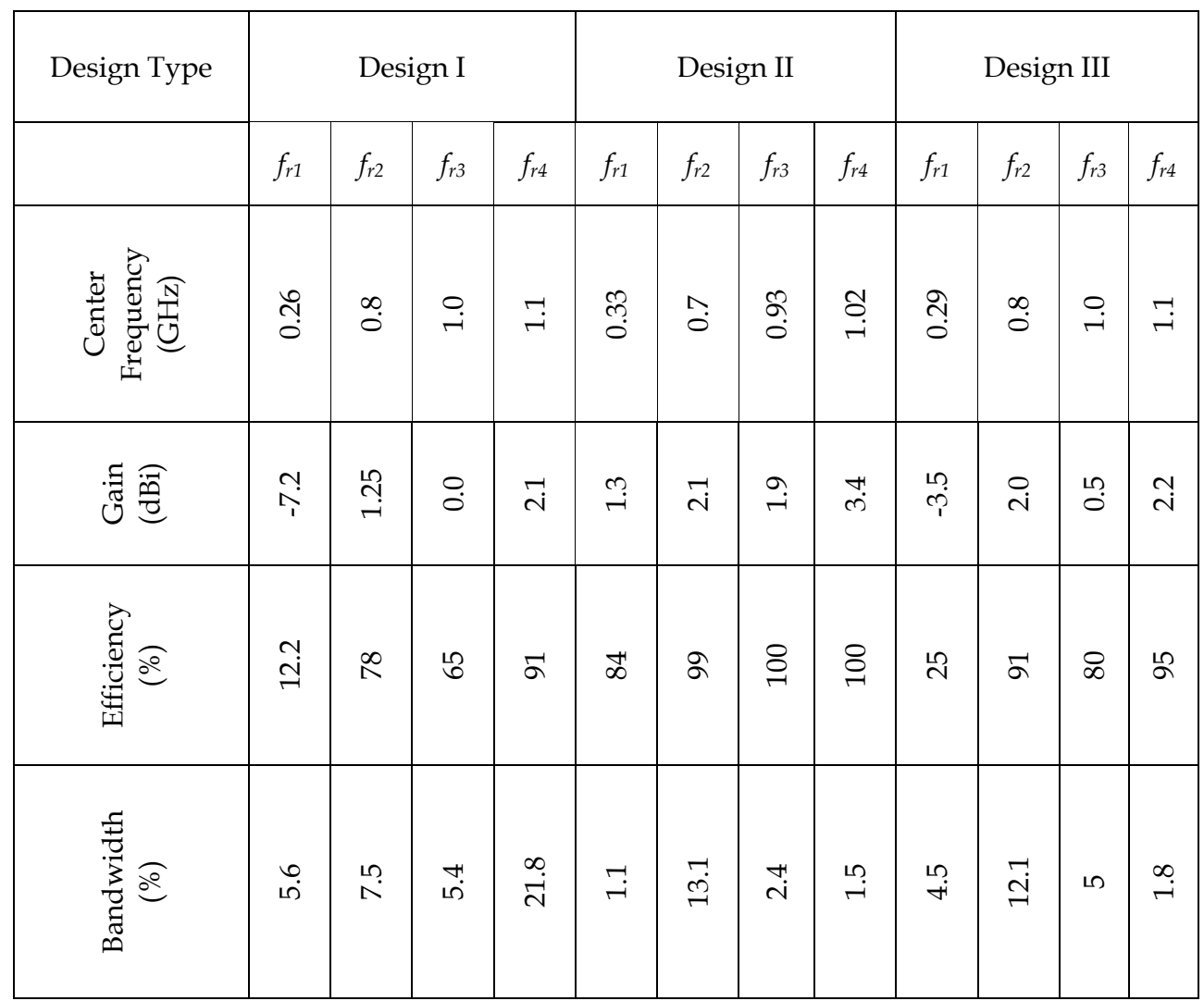

Table 2. Gain, efficiency, and bandwidth characteristics of the dipole antenna loaded with different DNG inclusions

The behaviors of the loaded dipole as a function of the plasma frequency for $d_{M I F}=72 \mathrm{~mm}$, have been also studied. Fig. 12 shows the antenna reflection coefficient for the dipoles loaded with ENG-, DNG-, and MNG-inclusions. It can be concluded from Fig. 12 that for the dipole antennas loaded with DNG- or ENG-inclusions, an additional resonance frequency is introduced at the frequencies lower than the antenna main resonant frequency. In addition, as can be seen from Fig. 12(a,b), in the DNG-loaded case, an additional resonance has been appeared, especially for higher values of plasma frequency, as compared to the ENG-loaded dipole. In contrast, for the dipoles loaded with MNG-inclusions, changing plasma frequency causes no resonances at frequencies lower than the main resonant frequency, as shown in Fig. 12(c).

In Fig. 13, the effect of permittivity and permeability of the DPS inclusions on the resonance frequency of the dipole antenna has been studied. As can be seen, increasing the permittivity of the loaded DPS results in a dual band operation in which the frequency separation ratio increases as the permittivity increases. However, for the dipoles loaded with magnetic inclusions, changing permeability causes no resonance frequency change. 


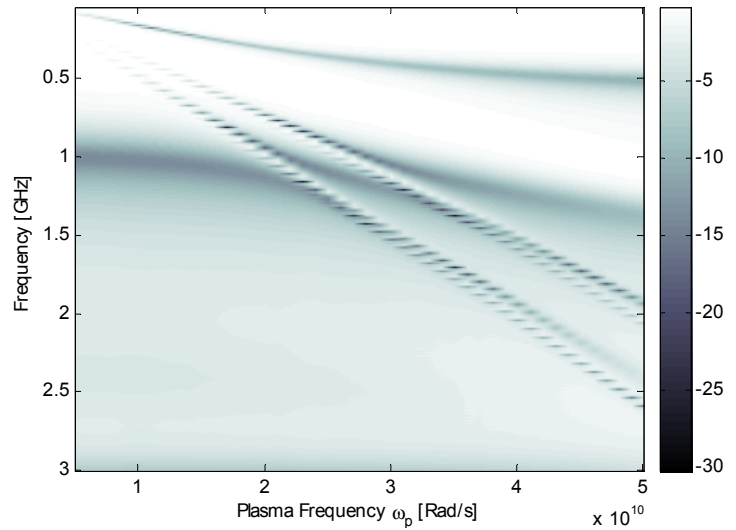

(a)

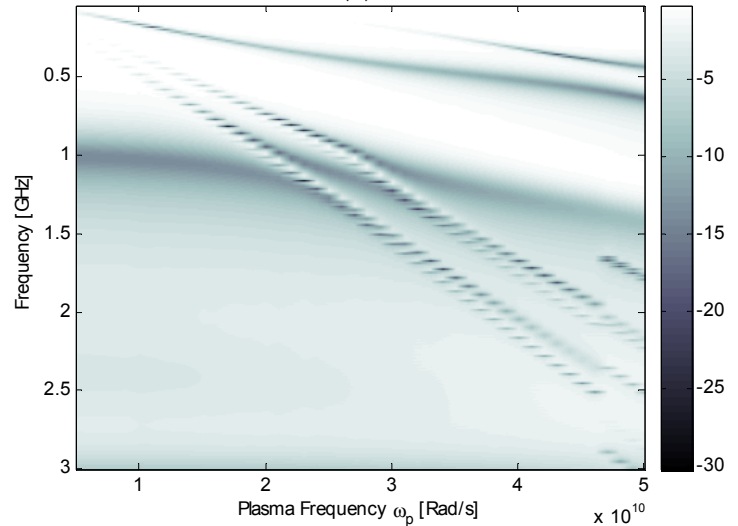

(b)

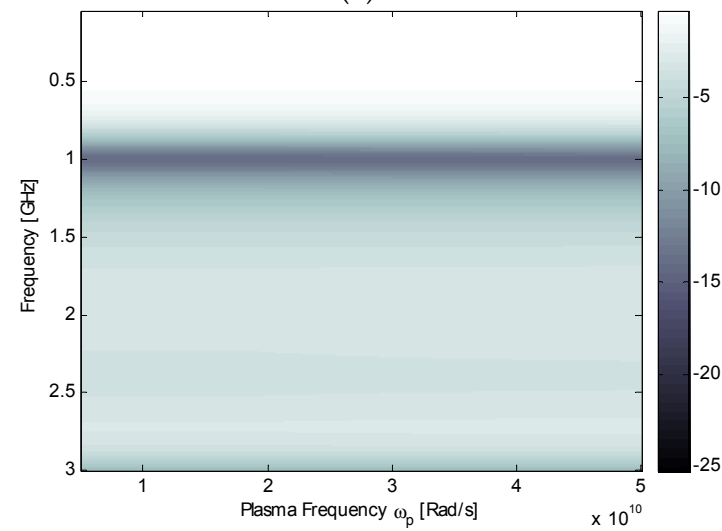

(c)

Fig. 12. CST simulation results for $\left|\mathrm{S}_{11}\right|[\mathrm{dB}]$ versus plasma frequency, $d_{M I F}=72 \mathrm{~mm}$, (a) ENG-, (b) DNG-, (c) MNG-inclusions. From (Jafargholi et. al., 2012), copyright (c) 2012 by the ACES Journal. 


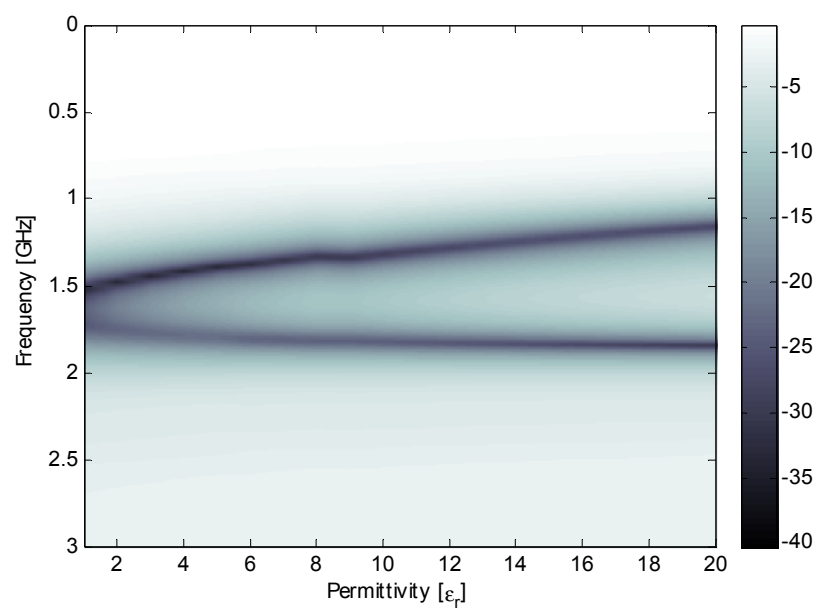

(a)

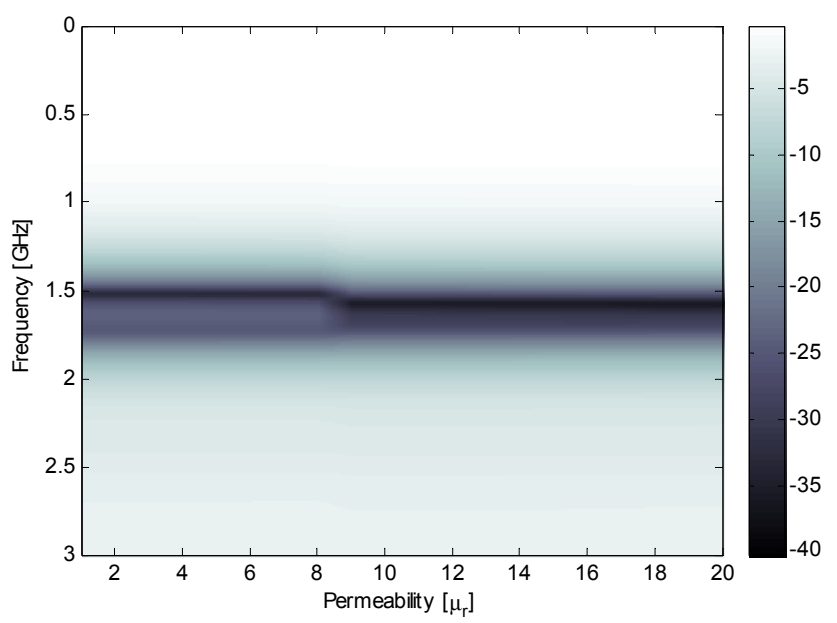

(b)

Fig. 13. CST simulation results for $\left|S_{11}\right|[\mathrm{dB}], d_{M I F}=45 \mathrm{~mm}$, versus material (a) permittivity, $\mu_{r}=1$, and (b) permeability, $\varepsilon_{r}=1$. From (Jafargholi et. al., 2012), copyright (C) 2012 by the ACES Journal.

The behaviors of the loaded dipole as a function of the inclusion width for $d_{M I F}=45 \mathrm{~mm}$, have been also studied. Fig. 14 shows the antenna reflection coefficient for the dipoles loaded with DPS-, ENG-, DNG-, and MNG-inclusions. It can be concluded from Fig. 14(c,d) that, for the dipole antennas loaded with DNG-/ENG- inclusions, the additional resonance frequency is significantly affected by the width of the inclusions. In contrast, for the dipoles loaded with DPS- and MNG-inclusions, changing inclusion widths causes no resonances at frequencies lower than the main resonant frequency, as shown in Fig. 14(a,b). 


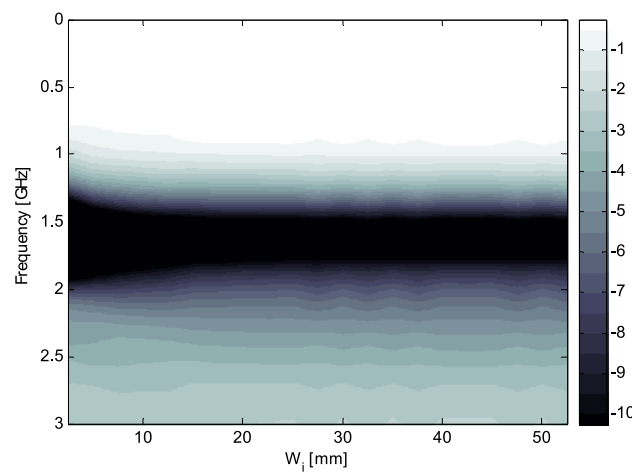

(a)

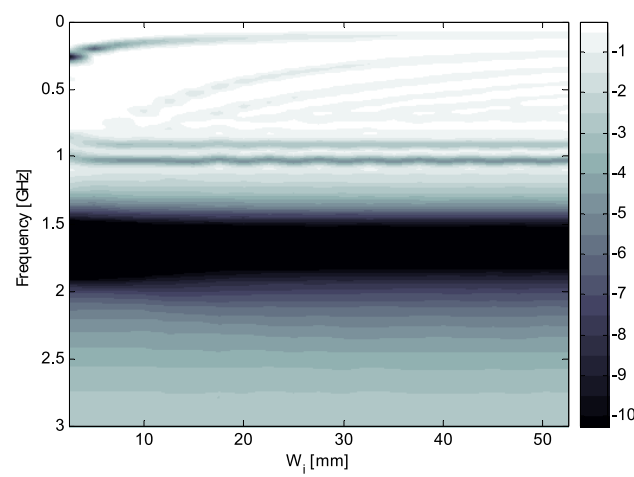

(c)

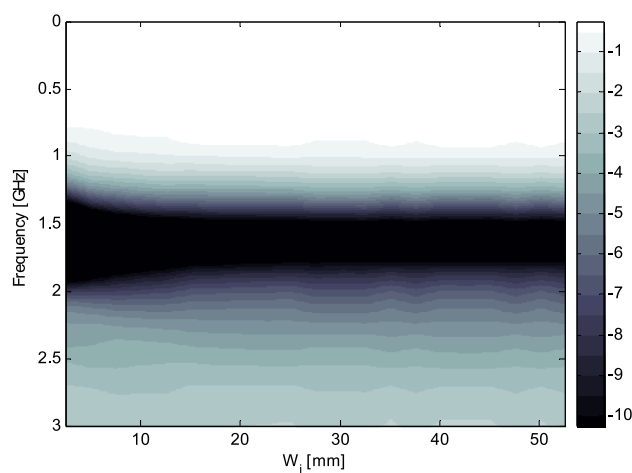

(b)

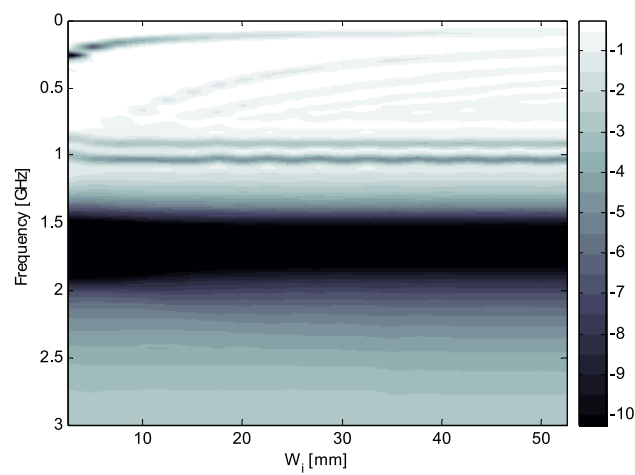

(d)

Fig. 14. CST simulation results for $\left|S_{11}\right|[\mathrm{dB}], d_{M I F}=45 \mathrm{~mm}$, versus width of (a) DPS-, (b) MNG-, (c) DNG- and (d) ENG-inclusions. From (Jafargholi et. al., 2012), copyright (C) 2012 by the ACES Journal.

\section{Simulations and realization}

In the previous section, it was revealed that the use of the ENG- and DNG-inclusions has led to a multi-resonance behavior. In this section, a new printed MTM cell is introduced to realize the ENG-inclusions. Fig. 15 shows a schematic of the proposed MTM cell along with its design parameters. The proposed MTM cell is printed on a FR4 substrate with a thickness of $0.8 \mathrm{~mm}$ and a dielectric constant of 4.4. An important feature of the proposed MTM is that it offers more degrees of freedom than conventional MTM cells (Engheta et al., 2006).

In order to retrieve the constitutive parameters of the proposed metamaterial, a unit cell positioned between two perfect electric conductors (PEC) in $x$ direction and two perfect magnetic conductors (PMC) in $z$ direction is simulated, and used to model an infinite periodic structure (Veysi et al., 2010). The resultant scattering parameters obtained from CST microwave studio are exerted to the Chen's algorithm (Veysi et al., 2010). The normalized impedance $(z)$ and refractive index $(n)$ of the under-study medium can be calculated as following: 


$$
\begin{gathered}
\mathrm{z}= \pm \sqrt{\frac{\left(1+\mathrm{s}_{11}\right)^{2}-\mathrm{s}_{21}^{2}}{\left(1-\mathrm{s}_{11}\right)^{2}-\mathrm{s}_{21}^{2}}}, \operatorname{real}(\mathrm{z}) \geq 0 \\
\mathrm{n}=\frac{1}{\mathrm{k}_{0} \mathrm{~d}}\left\{\left[\left[\ln \left(\mathrm{e}^{\mathrm{ink_{0 } \mathrm { d }}}\right)\right]^{\prime}+2 \mathrm{~m} \pi\right]-\mathrm{i}\left[\ln \left(\mathrm{e}^{\mathrm{ink} \mathrm{d}}\right)\right]\right\}
\end{gathered}
$$

Where

$$
\begin{gathered}
\operatorname{Im}(n) \geq 0, e^{\text {ink }_{0} \mathrm{~d}}=\frac{\mathrm{S}_{21}}{1-\mathrm{S}_{11} \frac{\mathrm{z}-1}{\mathrm{z}+1}} \\
\operatorname{Re}(\mathrm{n}(\omega))=1+\frac{2}{\pi} \mathrm{P} \cdot \mathrm{V} \cdot\left[\int_{0}^{\infty} \frac{\omega^{\prime} \operatorname{Im}\left(\mathrm{n}\left(\omega^{\prime}\right)\right)}{\omega^{\prime 2}-\omega^{2}} \mathrm{~d} \omega^{\prime}\right]
\end{gathered}
$$

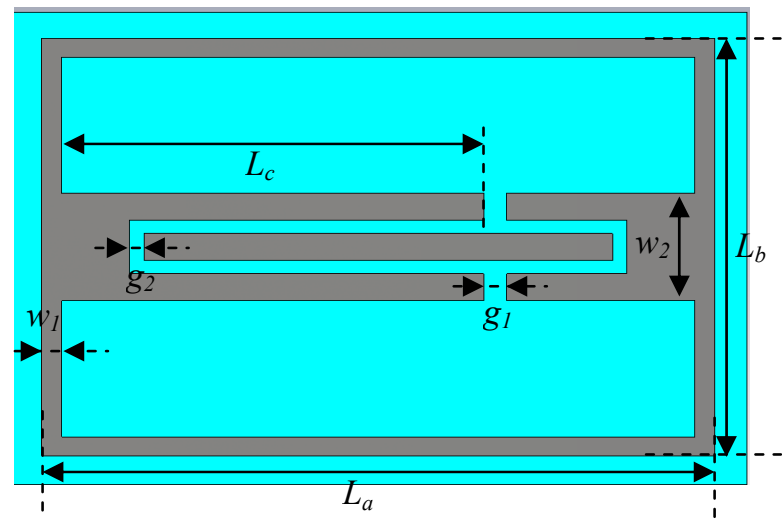

(a)

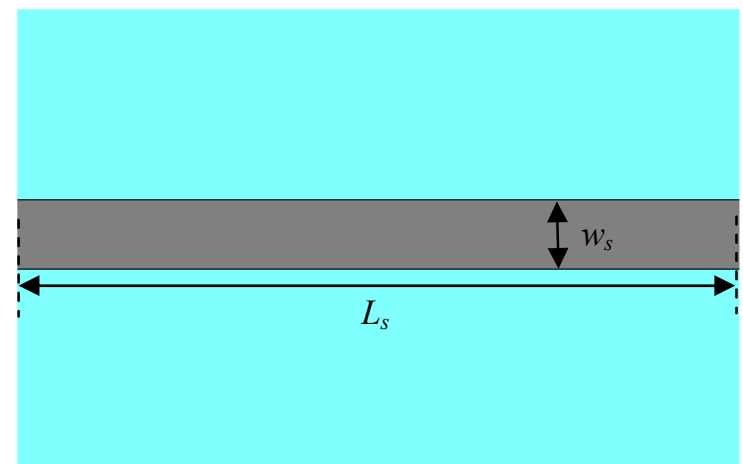

(b)

Fig. 15. Schematic of the proposed MTM unit cell and its design parameters, (a) front view, (b) back view: $L_{a}=23.54 \mathrm{~mm}, L_{b}=15.55 \mathrm{~mm}, L_{c}=14.78 \mathrm{~mm}, w_{1}=0.7 \mathrm{~mm}, g_{1}=0.8 \mathrm{~mm}, w_{2}=4 \mathrm{~mm}, g_{2}=$ $0.5 \mathrm{~mm}, w_{s}=2.5 \mathrm{~mm}$, and $L_{s}=26.75 \mathrm{~mm}$. From (Rafaei et al., 2011), copyright (C) 2011 by the IET Microwaves, Antennas \& Propagation. 
The ambiguity of the value of $m$ in (20) is resolved by using Kramers-Kronig (KK) relating the real and imaginary parts of the index of refraction (Lucarini et al., 2004). Where, P.V. denotes the principal value of the integral. The effective permittivity $(\varepsilon)$ and permeability $(\mu)$ of the medium can be expressed as: $\varepsilon=n / z, \mu=n z$. Fig. 16 shows the retrieved effective parameters of the proposed metamaterial cell. As can be seen, the proposed MTM cell has the permittivity that exhibits Drude behaviour at frequencies lower than $1.1 \mathrm{GHz}$ and Lorentz behaviour (Engheta et al., 2006) at frequencies higher than 1.1GHz.

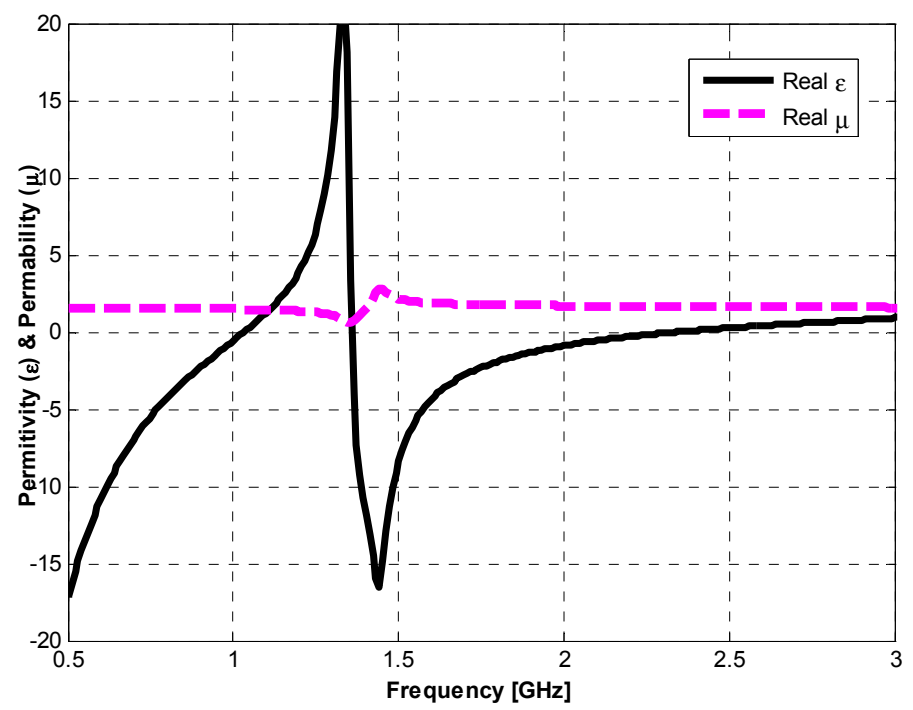

Fig. 16. Retrieved effective parameters of the Proposed MTM cell. From (Rafaei et al., 2011), copyright (C) 2011 by the IET Microwaves, Antennas \& Propagation.

Thus, this MTM can be approximated via a combination of Lorentz and Drude models. In order to realize the miniaturization method described previous section, double-sided printed dipole antenna is chosen for its simplicity in implementation and its low profile. Fig. 17 shows the proposed miniaturized printed dipole, in which a pair of proposed MTM cells is symmetrically added to each side of the printed dipole. The proposed MTM cells and dipole are printed on a FR4 substrate with a thickness of $0.8 \mathrm{~mm}$ and a dielectric constant of 4.4 to reduce the cost of the antenna and to make it more rigid in construction.

For the MTM cells that are far away from the dipole arms, the coupling levels of them with the dipole arms are low and thus the arrangement of the several MTM cells has no effect on the frequency behaviour of the proposed antenna. As a result, the dipole is just loaded with single cell MTM. Similar to the DNG- (Ziolkowski et al., 2003) and ENG- (Alu et al., 2003) MTMs, the proposed MTM cell can be modelled as a parallel resonant LC circuit. Thus, the proposed metamaterial cell is modelled as a resonant LC circuit parallel to the dipole, and the radiation into the free space is modelled as a resistor (Sievenpiper et al., 2006). A prototype of the proposed miniaturized dual-band printed dipole is fabricated to confirm the simulation results. Fig. 18 shows a photograph of the fabricated antenna. 


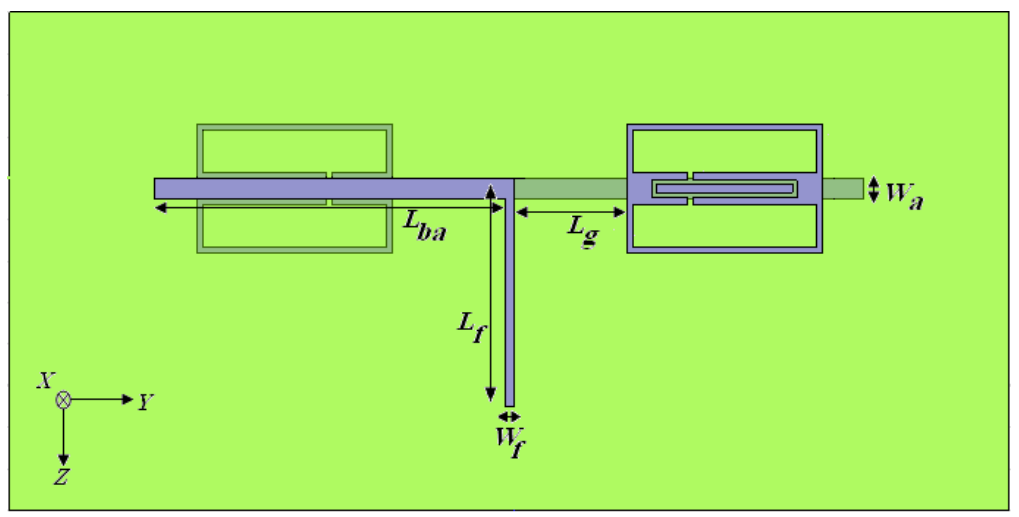

Fig. 17. Printed dipole symmetrically loaded with single cell MTM: $L_{b a}=42.05 \mathrm{~mm}$, $L_{f}=27.5 \mathrm{~mm}, L_{g}=12.52 \mathrm{~mm}, W_{a}=2.5 \mathrm{~mm}, W_{f}=0.8 \mathrm{~mm}$. From (Rafaei et al., 2011), copyright $(\subset$ 2011 by the IET Microwaves, Antennas \& Propagation.

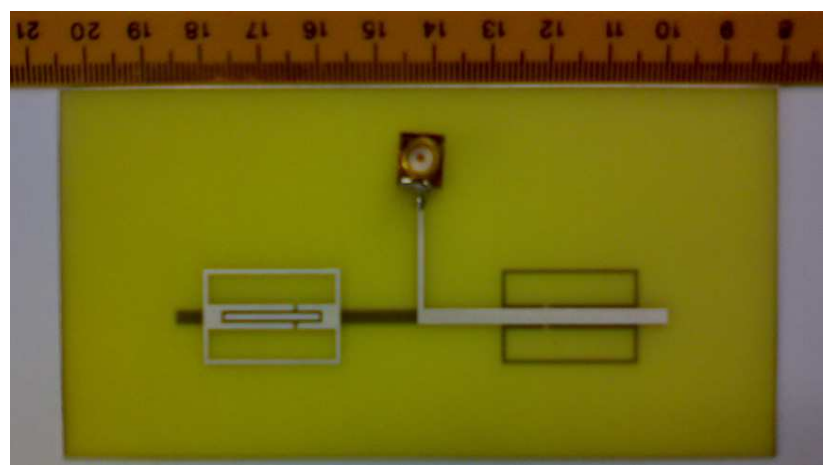

Fig. 18. Prototype of proposed miniaturized printed dipole antenna loaded with single cell MTM. From (Rafaei et al., 2011), copyright (c) 2011 by the IET Microwaves, Antennas \& Propagation.

Fig. 19 shows the reflection coefficient of the proposed symmetrically loaded dipole with the gap length, $\mathrm{g}_{1}$, of $0.8 \mathrm{~mm}$ as well as the unloaded dipole antenna. As can be seen, the dipole antenna along with the loading elements provides good matching at both resonance frequencies. For comparison purposes, a simple dipole antenna loaded with lossy ENG inclusions, with the same retrieved effective parameters of the proposed MTM cell (See Fig. 16), is also simulated. As can be seen from Fig. 19, the reflection coefficient of the dipole loaded with ENG inclusions correlates nicely to that obtained for the single cell MTM loaded dipole. The co-polarized and cross-polarized radiation patterns of the proposed loaded dipole are measured at the resonant frequencies of $940 \mathrm{MHz}$ and $1.7 \mathrm{GHz}$.

The measured and simulated radiation patterns at first and second resonant frequencies are shown in Fig. 20. As expected, the radiation patterns at both resonant frequencies are similar to that of the conventional unloaded dipole antenna. The gain of the proposed antenna at low resonant frequency is high compared to that of the other miniaturized MTM loaded dipoles (Iizuka et al., 2006; Iizuka et al., 2007; Borja et al., 2007; Rafaei et al., 2010). 


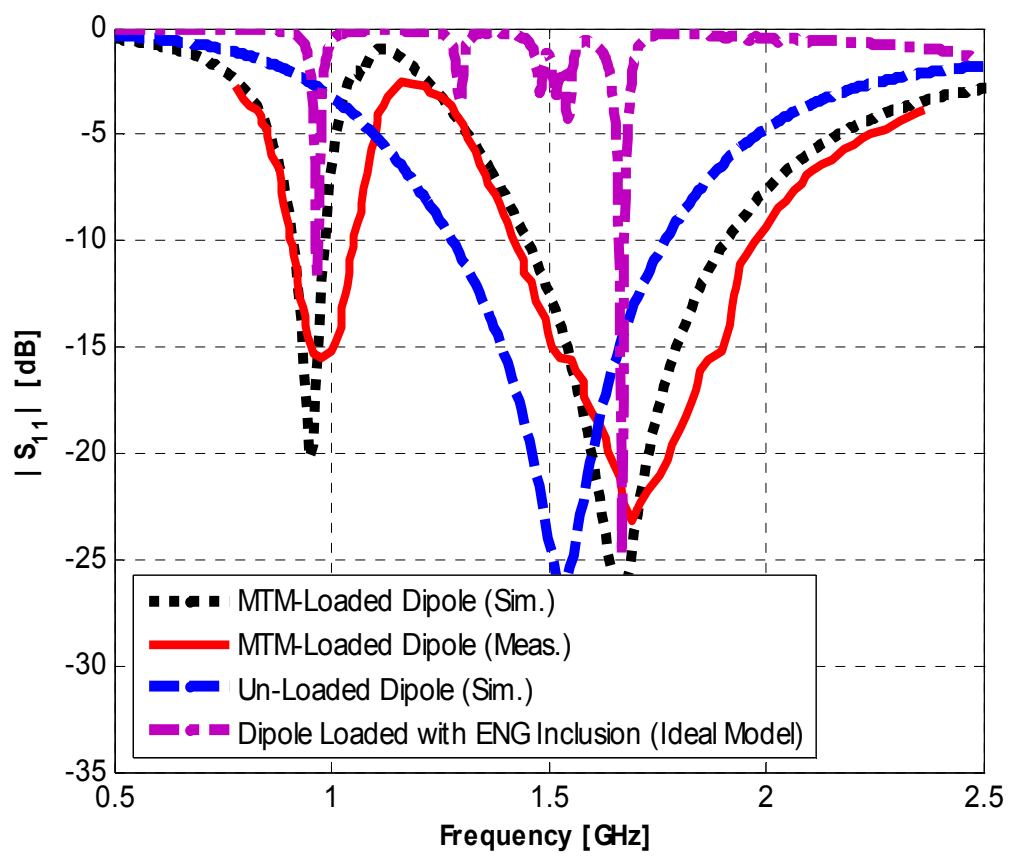

Fig. 19. Reflection coefficient of the proposed miniaturized printed dipole antenna loaded with single cell MTM. As a reference, an unloaded dipole and an ideal model of the ENGLoaded dipole are also simulated. From (Rafaei et al., 2011), copyright (C) 2011 by the IET Microwaves, Antennas \& Propagation.

The antenna gains at first and second resonant frequencies are $-2.679 \mathrm{dBi}$ and $1 \mathrm{dBi}$, respectively. The proposed antenna has a broad bandwidth of $15.96 \%$ at $940 \mathrm{MHz}$ (which is significantly wider than the bandwidth of other miniaturized MTM loaded dipoles (Iizuka et al., 2006; Iizuka et al., 2007; Borja et al., 2007; Rafaei et al., 2010)) and 32.35\% at 1.7GHz. An important advantage of the proposed antenna is that the dipole length does not need to be increased to lower the resonant frequency. Consequently, a compact antenna is obtained.

Finally, the effect of the MTM location is investigated to obtain some engineering guidelines for loaded dipole designs. Thus, the loading elements move along the antenna arms and the antenna reflection coefficient is plotted in Fig. 21 for each stage. The gain, bandwidth and efficiency of the loaded dipoles with different MTM locations are also compared in Table 3.

As can be seen, the first resonant frequency remains approximately unchanged while the second one reduces as the MTM cells move away from the antenna feed point. Thus, when the MTM elements move closer to the dipole ends, the separation of the two resonances decreases. In addition, when the MTM cells are placed close to the antenna feed point, the proposed antenna cannot match very well to a $50 \Omega$ transmission line. Moreover, as can be 
seen from Figs. 10, 11 and 21 the single cell MTM loaded printed dipole follows closely the frequency behavior of the dipole antenna loaded with cylindrical dispersive ENGinclusions, as $d_{M I F}$ or $L_{g}$ increases.
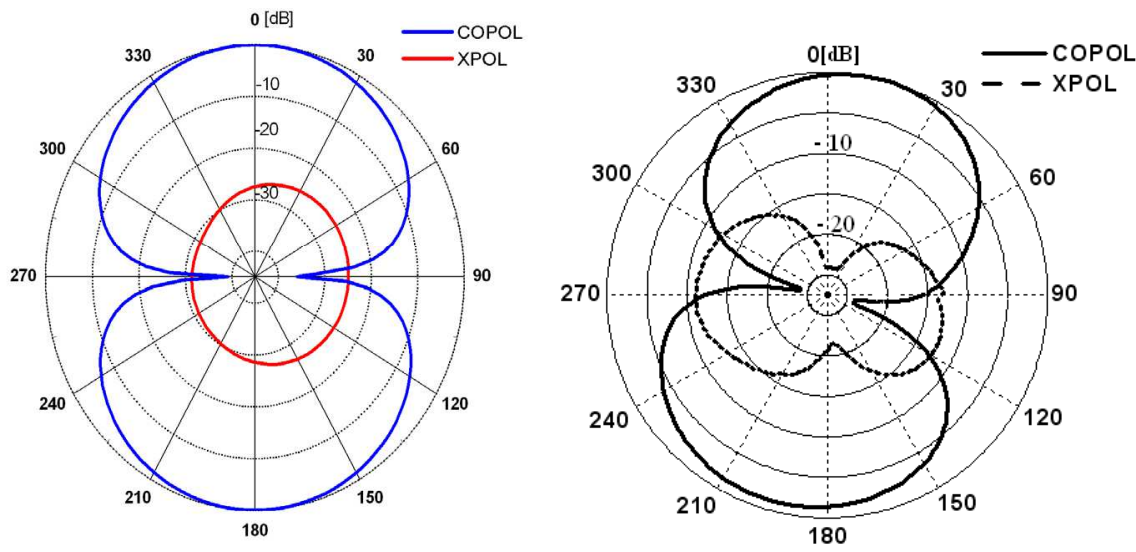

(a)
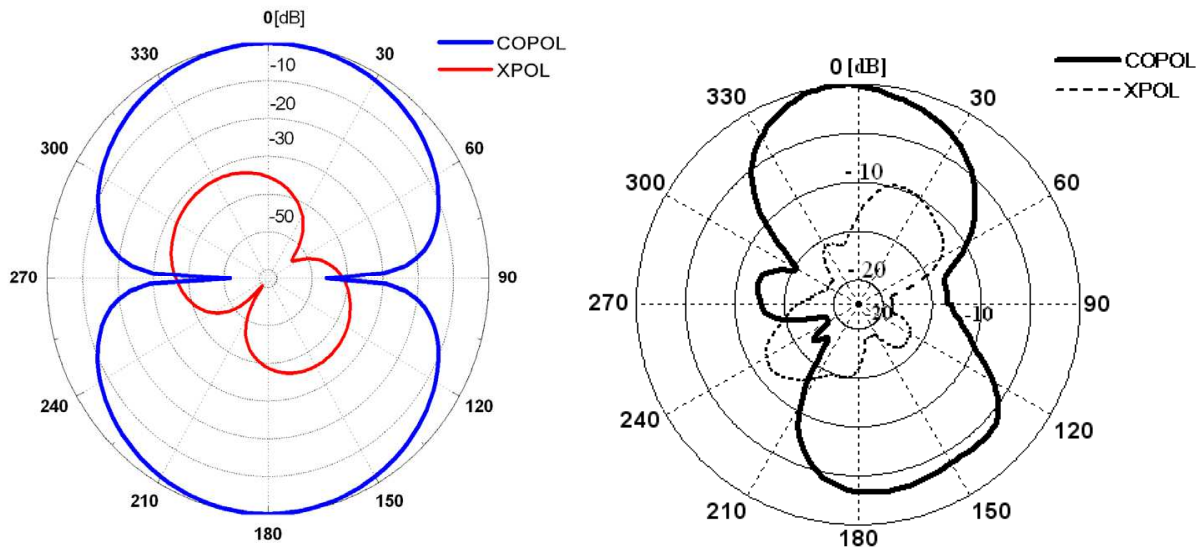

(b)

Fig. 20. Radiation patterns of the proposed printed dipole antenna at (a) $940 \mathrm{MHz}$ and (b) 1.7GHz. (Right hand figures are measurements). From (Rafaei et al., 2011), copyright (C 2011 by the IET Microwaves, Antennas \& Propagation.

In the previous design, a printed dipole was symmetrically loaded with single cell MTMs to realize a dual band operation. Here, the design parameters of the proposed dual band antenna are changed to provide a tri-band dipole antenna. As a result, two different tri-band 
printed dipoles are provided in the following subsections. Since changing the locations and dimensions of the MTM cells does not have any significant effect on the antenna radiation patterns, the proposed antennas radiate omnidirectional radiation patterns at all resonant frequencies. However, these are not plotted here for the sake of brevity.

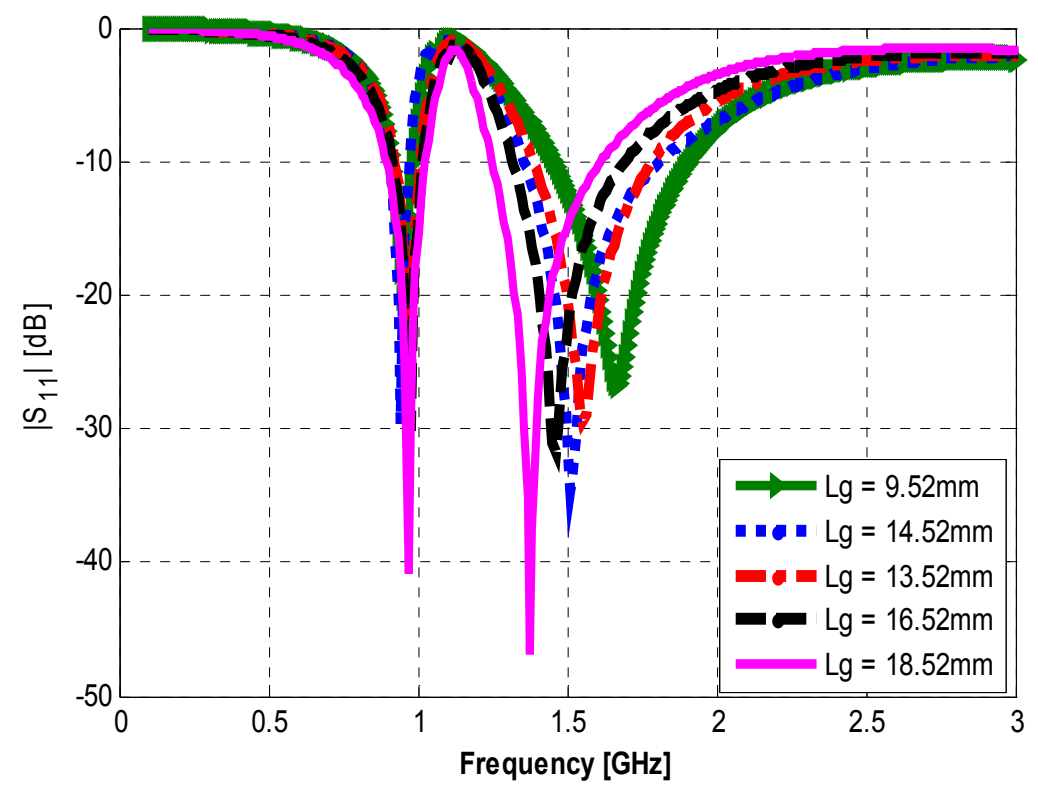

Fig. 21. The effect of MTM location on the reflection coefficient of the printed dipole antenna. From (Rafaei et al., 2011), copyright (C 2011 by the IET Microwaves, Antennas \& Propagation.

\section{Acknowledgment}

The authors would like to thank Iran Telecommunication Research Centre (ITRC) for its financial supports.

\section{References}

Alu A. , and Engheta N.; "Pairing an Epsilon-Negative Slab With a Mu-Negative Slab: Resonance, Tunneling and Transparency" IEEE Trans. Antennas Propagat., vol. 51, pp. 2558-2571, Oct. 2003.

Balanis C. A., Advanced Engineering Electromagnetics. New York: Wiley, 1989.

Beggs R., Luebbers J., and Chamberlin K., "Finite difference time-domain calculation of transients in antennas with nonlinear loads," IEEE Trans. Antennas Propag., vol. 41, no.5, pp.566-, May 1993. 
Borja A. L., Hall P. S., Liu Q. and Iizuka H., “Omnidirectional left-handed loop antenna," IEEE Antennas and Wireless Propagation Lett., Vol. 6, 495-498, 2007.

Collin R. E., and Zucker F. J., Antenna Theory, McGraw-Hill, 1969.

Engheta N. and Ziolkowski R., Metamaterials: Physics and Engineering Explorations, John Wiley \& Sons Inc., 2006.

Erentok A., and Ziolkowski R. W., "Metamaterial-Inspired Efficient Electrically Small Antennas" IEEE Trans. Antennas Propagat., vol. 56, pp. 691-707, March 2008.

Erentok A., Luljak P., and Ziolkowski R. W., "Antenna performance near a volumetric metamaterial realization of an artificial magnetic conductor," IEEE Trans. Antennas Propagat., vol. 53, pp. 160-172, Jan. 2005.

Iizuka H. and Hall P. S., "Left-handed dipole antennas and their implementations," IEEE Trans. Antennas Propag., vol. 55, no. 5, 1246-1253, May 2007.

Iizuka H., Hall P. S., and Borja A. L., "Dipole antenna with left-handed loading," IEEE Antennas Wireless Propag. Lett., vol. 5, pp. 483-485, 2006.

Jafargholi A., and Kamyab M., Full-Wave Analysis of Double Positive/Double Negative Loaded Dipole Antennas, Electromagnetics, 32:2, 103-116, (2012).

Jafargholi A., and Kamyab M., Metamaterials in Antenna Engineering, Theory and Applications, LAP Lambert Academic Publishing, Germany, 2011.

Jafargholi A., Kamyab M., and Veysi M., “Artificial magnetic conductor loaded monopole antenna" IEEE Antennas Wireless Propag. Lett., vol. 9, pp. 211-214, 2010.

Jafargholi A., Kamyab M., Rafaei M., Veysi M., “A compact dual-band printed dipole antenna loaded with CLL-based metamaterials", International Review of Electrical Engineering, vol. 5, no. 6, 2710-2714, 2010.

Kennedy T. F., Fasenfest K. D., Long S. A. and Williams J. T., “Modification and Control of Currents on Electrically Large Wire Structures Using Composite Dielectric Bead Elements, “IEEE Trans. Antennas Propag., vol. 54, no. 12, 3608-3613, 2006.

Kraus J. D., and Marhefka R. J., Antennas for All Applications, McGraw-Hill, 2002.

Liu Q., Hall P. S., and Borja A. L.," Efficiency of Electrically Small Dipole Antennas Loaded With Left-Handed Transmission Lines," IEEE Trans. Antennas Propagat., vol. 57, no. 10, pp. 3009-3017, Oct. 2009.

Lucarini V., Saarinen J. J., Peiponen K. E., and Vartiainen E. M., “Kramers-Kronig Relation in Optical Materials Research", Springer Series in optical sciences, 2004.

Mosallaei H., and Sarabandi K., "Design and Modeling of Patch Antenna Printed on Magneto-Dielectric Embedded-Circuit Metasubstrate" IEEE Trans. Antennas Propag., vol. 55, no. 1, 1031-1038, Jan 2007.

Ock J. S., and Eom H. J., "Radiation of a Hertzian Dipole in a Slotted Conducting Sphere," IEEE Trans. Antennas Propagat., vol. 57, nov 12, pp. 3847-3851, Dec. 2009.

Polk C., "Resonance and Supergain Effects in Small Ferromagnetically or Dielectrically Loaded Biconical Antennas, "IRE Trans. Antennas Propag., pp. 414-423; December, 1959. 
Rafaei M., Kamyab M., Jafargholi A., and Mousavi S. M., "Analytical modeling of the printed dipole antenna loaded with CRLH structures," Progress In Electromagnetics Research B, vol. 20, 167-186, 2010.

Rogers S. D., Butler C. M., and Martin A. Q., "Design and Realization of GA-Optimized Wire Monopole and Matching Network With 20:1 Bandwidth" IEEE Trans. Antennas Propag., vol. 51, no. 3, pp. 493-502, March. 2003.

Saoudy S. A. and Hamid M., "Input admittance of a biconical antenna with wide feed gap," IEEE Trans. Antennas Propag., vol. 38, no. 11, pp. 1784-1790, Nov. 1990

Shams K. M. Z. and Ali M., "Analyses of a Dipole Antenna Loaded by a Cylindrical Shell of Double Negative (DNG) Metamaterial," International Journal of Antennas and Propagation, vol. 2007, Article ID 97481, 10 pages.

Sievenpiper D., "Chapter11: Review of theory, fabrication, and applications of high impedance ground planes," in Metamaterials: Physics and Engineering Explorations, edited by Erentok A., and Ziolkowski R. W. 


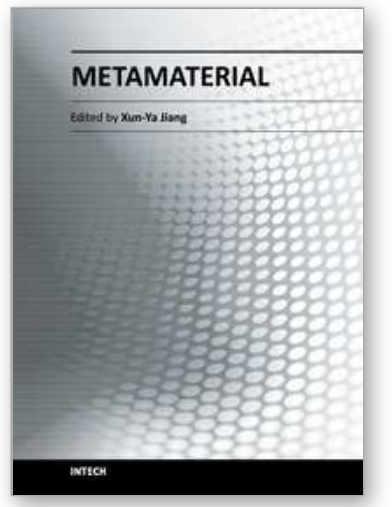

\author{
Metamaterial \\ Edited by Dr. Xun-Ya Jiang
}

ISBN 978-953-51-0591-6

Hard cover, 620 pages

Publisher InTech

Published online 16, May, 2012

Published in print edition May, 2012

In-depth analysis of the theory, properties and description of the most potential technological applications of metamaterials for the realization of novel devices such as subwavelength lenses, invisibility cloaks, dipole and reflector antennas, high frequency telecommunications, new designs of bandpass filters, absorbers and concentrators of EM waves etc. In order to create a new devices it is necessary to know the main electrodynamical characteristics of metamaterial structures on the basis of which the device is supposed to be created. The electromagnetic wave scattering surfaces built with metamaterials are primarily based on the ability of metamaterials to control the surrounded electromagnetic fields by varying their permeability and permittivity characteristics. The book covers some solutions for microwave wavelength scales as well as exploitation of nanoscale EM wavelength such as visible specter using recent advances of nanotechnology, for instance in the field of nanowires, nanopolymers, carbon nanotubes and graphene. Metamaterial is suitable for scholars from extremely large scientific domain and therefore given to engineers, scientists, graduates and other interested professionals from photonics to nanoscience and from material science to antenna engineering as a comprehensive reference on this artificial materials of tomorrow.

\title{
How to reference
}

In order to correctly reference this scholarly work, feel free to copy and paste the following:

Amir Jafargholi and Manouchehr Kamyab (2012). Investigation of Dipole Antenna Loaded with DPS and DNG Materials, Metamaterial, Dr. Xun-Ya Jiang (Ed.), ISBN: 978-953-51-0591-6, InTech, Available from: http://www.intechopen.com/books/metamaterial/investigation-of-wire-antenna-loaded-with-dps-and-dngmaterials

\section{INTECH}

open science | open minds

InTech Europe

University Campus STeP Ri

Slavka Krautzeka 83/A

51000 Rijeka, Croatia

Phone: +385 (51) 770447

Fax: +385 (51) 686166

www.intechopen.com
InTech China

Unit 405, Office Block, Hotel Equatorial Shanghai

No.65, Yan An Road (West), Shanghai, 200040, China

中国上海市延安西路 65 号上海国际贵都大饭店办公楼 405 单元

Phone: +86-21-62489820

Fax: +86-21-62489821 
(C) 2012 The Author(s). Licensee IntechOpen. This is an open access article distributed under the terms of the Creative Commons Attribution 3.0 License, which permits unrestricted use, distribution, and reproduction in any medium, provided the original work is properly cited. 